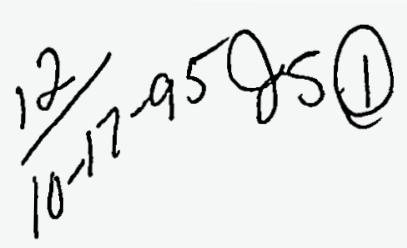

UCRL-ID-121679

\title{
Closed-Form Approach to Checking Frame Design
}

\section{Alex Blake}

April 5, 1995

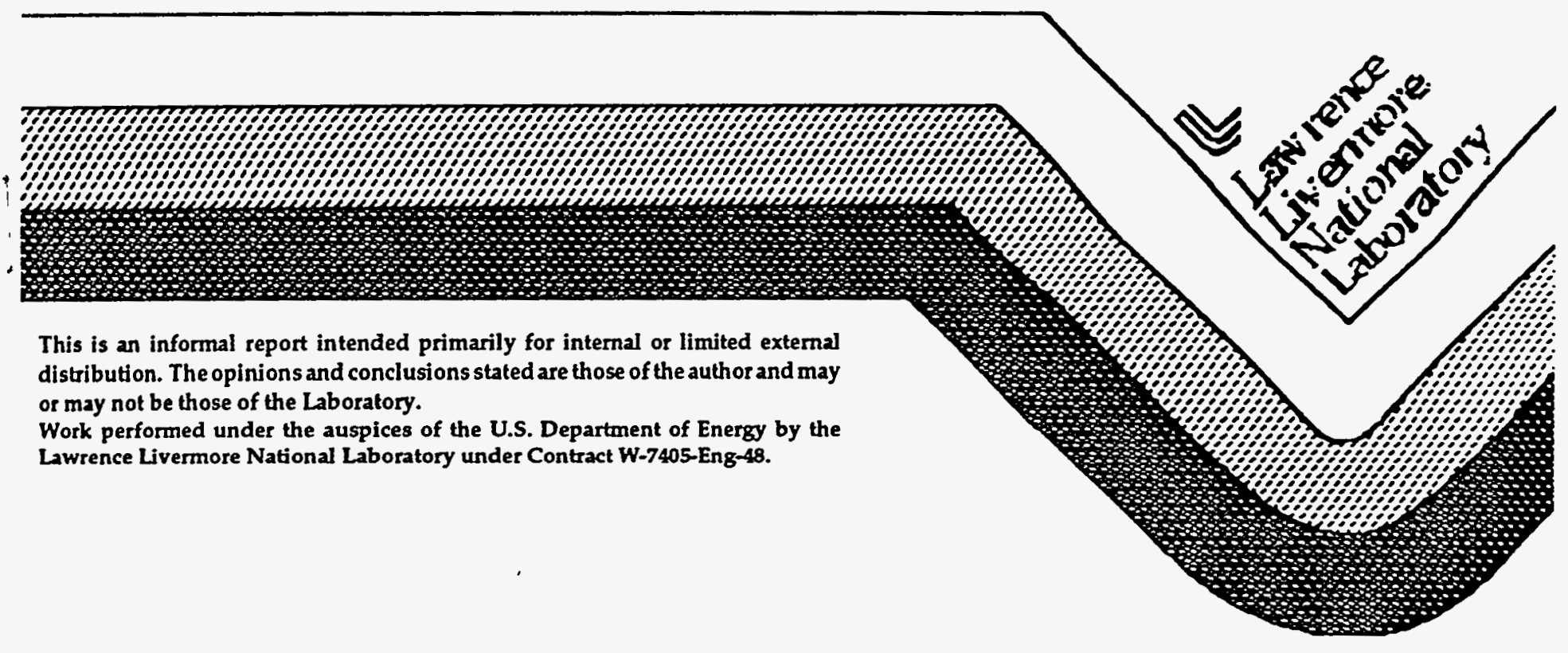

\section{MASTER}




\section{DISCLAIMER}

This document was prepared as an account of work sponsored by an agency of the United States Government. Neither the United States Government nor the University of California nor any of their employees, makes any warranty, express or implied, or assumes any legal liability or responsibility for the accuracy, completeness, or usefulness of any information, apparatus, product, or process disclosed, or represents that its use would not infringe privately owned rights. Reference herein to any specific commercial product, process, or service by trade name, trademark, manufacturer, or otherwise, does not necessarily constitute or imply its endorsement, recommendation, or favoring by the United States Government or the University of Califomia. The views and opinions of authors expressed herein do not necessarily state or reflect those of the United States Government or the University of California, and shall not be used for advertising or product endorsement purposes.

This report has been reproduced directly from the best available copy.

Available to DOE and DOE contractors from the Office of Scientific and Technical Information P.O. Box 62, Oak Ridge, TN 37831

Prices available from (615) 576-8401, FTS 626-8401

Available to the public from the

National Technical Information Service

U.S. Department of Commerce

5285 Port Royal Rd.

Springfield, VA 22161 


\section{DISCLAIMER}

Portions of this document may be illegible in electronic image products. Images are produced from the best available original document. 


\section{Closed-Form Approach}

to

\section{Checking Frame Design}




\section{Contents}

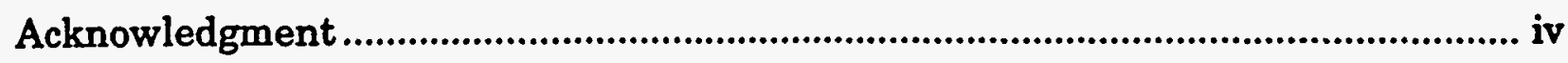

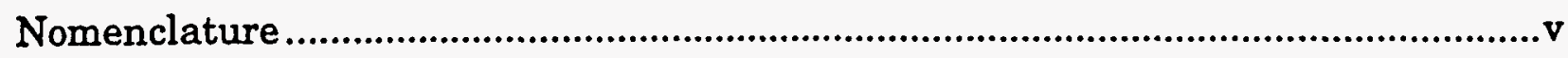

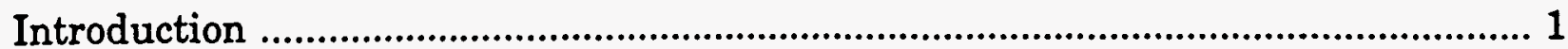

Half-Ring Model ...................................................................................... 1

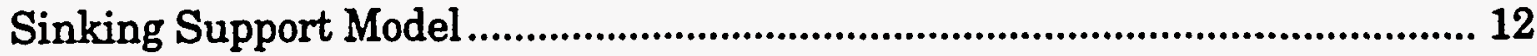

Other Deflection Models .............................................................................. 23

Strength of Plate Corners ....................................................................... 29

Comments on Fracture Resistance ...................................................... 41

Summary and Conclusions ............................................................................... 45

References .............................................................................................. 46 


\section{Acknowledgment}

The author wishes to thank Project Engineers V. P. Brugman and T. A. Decker for their continued support, technical monitoring of the study and undisputed interest in this report.

The author is also indebted to M. A. Gerhard for supplying the critical computer data and for his professional attitude in sharing his knowledge for the benefit of the project.

This work was performed under the auspices of the U.S. Department of Energy by Lawrence Livermore National Laboratory under contract No. W-7405-Eng-48. 


\section{Nomenclature}

\begin{tabular}{|c|c|}
\hline$A_{c}$ & Corner area, in..$^{2}\left(\mathrm{~mm}^{2}\right)$ \\
\hline $\mathbf{A}_{\mathbf{i}}$ & Projected ring area, in. ${ }^{2}\left(\mathrm{~mm}^{2}\right)$ \\
\hline $\mathbf{A}_{8}$ & Area of sector, in. ${ }^{2}\left(\mathrm{~mm}^{2}\right)$ \\
\hline $\mathbf{A}_{\mathbf{t}}$ & Total area, in. ${ }^{2}\left(\mathrm{~mm}^{2}\right)$ \\
\hline $\mathbf{a}$ & Plate dimension, in. (mm) \\
\hline $\mathbf{a}$ & Length or depth of crack, in. (mm) \\
\hline aCR & Critical crack length, in. (mm) \\
\hline $\mathbf{B}$ & Thickness (in Fracture Mechanics), in. (mm) \\
\hline $\mathbf{B}_{\mathbf{3}}, \mathbf{B}_{\mathbf{7}}$ & Constants for arched cantilever \\
\hline b & Width of section, in. (mm) \\
\hline $\mathbf{C}_{\mathbf{k}}$ & Constant in formula for $K$ \\
\hline $\mathbf{C}_{\boldsymbol{B}}$ & Constant in formula for $\mathrm{K}_{\mathbf{8}}$ \\
\hline c & Half depth of section, in. (mm) \\
\hline c & Half length of elliptical crack, in. (mm) \\
\hline $\mathbf{D}_{\mathbf{2}}$ & Constant for moment (multiple support) \\
\hline $\mathbf{D}_{4}$ & Constant for twist (multiple support) \\
\hline $\mathbf{D}_{5}, \mathbf{D}_{6}$ & Constant in out-of-plane loading \\
\hline $\mathbf{E}$ & Elastic modulus, psi (MPa) \\
\hline $\mathbf{f}$ & Natural frequency, $\mathrm{Hz}$ \\
\hline G & Elastic shear modulus, psi (MPa) \\
\hline h & Depth of section, in. (mm) \\
\hline $\mathbf{I}$ & Moment of inertia, in. ${ }^{4}\left(\mathrm{~mm}^{4}\right)$ \\
\hline $\mathbf{I}_{\mathbf{u}}$ & Moment of inertia (upper plate), in. ${ }^{4}\left(\mathrm{~mm}^{4}\right)$ \\
\hline $\mathbf{I}_{\mathbf{l}}$ & Moment of inertia (lower plate), in. ${ }^{4}\left(\mathrm{~mm}^{4}\right)$ \\
\hline $\mathbf{K}$ & Torsional shape factor, in. ${ }^{4}\left(\mathrm{~mm}^{4}\right)$ \\
\hline $\mathbf{K}^{*}$ & Buckling factor \\
\hline $\mathbf{K}_{\mathbf{c}}$ & Plane stress fracture toughness, ksi (in.) $)^{1 / 2}\left[\mathrm{MPa}(\mathrm{m})^{1 / 2}\right]$ \\
\hline $\mathbf{K}_{\mathbf{I}}$ & Stress intensity factor, ksi (in.) $)^{1 / 2}\left[\mathrm{MPa}(\mathrm{m})^{1 / 2}\right]$ \\
\hline $\mathbf{K}_{\mathbf{I c}}$ & Plane strain fracture toughness, $\mathrm{ksi}(\mathrm{in} .)^{1 / 2}\left[\mathrm{MPa}(\mathrm{m})^{1 / 2}\right]$ \\
\hline $\mathbf{K}_{\max }$ & Maximum stress intensity, ksi (in.) $)^{1 / 2}\left[\mathrm{MPa}(\mathrm{m})^{1 / 2}\right]$ \\
\hline $\mathbf{K}_{\mathbf{8}}$ & Section modulus for torsion, in. ${ }^{3}\left(\mathrm{~mm}^{3}\right)$ \\
\hline $\mathbf{L}$ & Length, in. (mm) \\
\hline $\mathbf{M}$ & Bending moment, lb-in. (N-mm) \\
\hline $\mathbf{M}_{\mathbf{f}}$ & Fixing moment, lb-in. (N-mm) \\
\hline $\mathbf{M}_{\mathbf{0}}$ & Bending moment (double cantilever), lb-in. ( $\mathrm{N}-\mathrm{mm}$ ) \\
\hline
\end{tabular}




$\begin{array}{ll}\mathbf{M}_{\mathbf{K}} & \text { Correction factor } \\ \mathbf{n} & \text { Number of supports } \\ \mathbf{Q} & \text { Flaw shape factor } \\ \mathbf{q} & \text { Load per inch, lb/in. (N/mm) } \\ \mathbf{R} & \text { Mean radius, in. (mm) } \\ \mathbf{R}_{\mathbf{i}} & \text { Inner radius, in. (mm) } \\ \mathbf{R}_{\mathbf{0}} & \text { Outer radius, in. (mm) } \\ \mathbf{r} & \text { Auxiliary radius, in. (mm) } \\ \mathbf{S}_{\mathbf{b}} & \text { Bending stress, psi (MPa) } \\ \mathbf{S}_{\mathbf{C R}} & \text { Critical buckling stress, psi (MPa) } \\ \mathbf{S}_{\mathbf{y}} & \text { Yield strength, psi (MPa) } \\ \mathbf{T} & \text { Twisting moment, lb-in. (N-mm) } \\ \mathbf{t} & \text { Thickness of plate, in. (mm) } \\ \mathbf{t}_{\mathbf{u}} & \text { Thickness of upper plate, in. (mm) } \\ \mathbf{t}_{\mathbf{l}} & \text { Thickness of lower plate, in. (mm) } \\ \mathbf{W} & \text { Concentrated load, lb (N) } \\ \mathbf{W}_{\mathbf{u}} & \text { Load on upper plate, lb (N) } \\ \mathbf{W}_{\mathbf{l}} & \text { Load on lower plate, lb (N) } \\ \mathbf{W}_{\mathbf{t}} & \text { Total load, lb (N) } \\ \mathbf{Y} & \text { Deflection, in. (mm) } \\ \mathbf{Y}_{\mathbf{1}} & \text { Deflection of arched cantilever, in. (mm) } \\ \mathbf{Y}_{\mathbf{2}} & \text { Deflection of straight cantilever, in. (mm) } \\ \mathbf{Y}_{\mathbf{t}} & \text { Total deflection, in. (mm) } \\ \mathbf{Y}_{\mathbf{z}} & \text { Deflection in z direction (Fig. 20), in. (mm) } \\ \mathbf{Z} & \left.\text { Section modulus, in. }{ }^{3}(\mathrm{~mm})^{3}\right) \\ \boldsymbol{\delta}_{\mathbf{s t}} & \text { Static deflection, in. (mm) } \\ \boldsymbol{\eta} & \text { Angle of twist, rad } \\ \boldsymbol{\theta} & \text { Arbitrary angle, deg } \\ \lambda & \text { Ratio of flexural to torsional rigidity } \\ \boldsymbol{\gamma} & \text { Poisson's ratio } \\ \mathbf{\tau} & \text { Subtended angle } \\ & \text { Shear stress, psi (MPa) } \\ & \end{array}$




\section{Introduction}

This brief report contains calculations of deflections and stresses of the support frame on the XMM project. The goal is to provide an independent view of structural integrity of the frame utilizing a noncomputer approach to design based on elementary closed form solutions and approximate models of mechanical and structural behavior. It is recognized that full confidence can only be assured when computer generated results pertaining to the critical areas and features of the integrating structure can be enveloped by the bracketing solutions. Such solutions help to establish the correct order of the numerical values and the physical meaning of the parameters involved. With the tremendous emphasis on the proliferation of computer software and growing difficulties in applying quality assurance principles to computer codes, the dual analytical approach to engineering design cannot be ignored. Dual approach means computer code evaluation with closed-form cross-checking of stresses and strains in critical areas.

Although the computer solutions have come from the three independent sources, this report utilizes the numerical values from the LLNL studies represented by the computer runs and analysis of the critical elements of the frame. This information includes the computer-generated illustrations, numerical results, and interpretations of three-dimensional details by Michael Gerhard. The selection of the critical locations of the frame has been specified by Todd Decker.

Since the frame geometry, deformation patterns, and the nature of loading are highly complex, this study is restricted to simplified models of selected areas of the structure which can be handled by the conventional formulas and reasonable approximations. The maximum loading is assumed to be pseudo-static and the structural response is elastic. The individual components are expected to behave as beams, plates, or curved members and certain geometrical approximations cannot be avoided. However, experience shows that many simplified geometrical features are acceptable in calculating the ball-park numbers of stresses and strains. The scope of this study is not to prove absolute agreement between the finite element and the closed form, but to show that both results are of the same order of magnitude and the acceptable level of conservatism. The calculations should also indicate whether the design is governed by the stress or deflection/criteria.

This report contains some comments related to material properties, stress concentration, and elements of fracture mechanics directly applicable to frame analysis and design. Such topics and parameters fall usually outside the finite element modeling, but they can have a crucial influence on the mechanical and structural performance of the systems at hand.

\section{Half-Ring Model}

The first supplementary design check of the support frame is concerned with approximating the behavior of the structure by a half-ring. The model is assumed to contain three extreme portions of the frame denoted by A, B, and C, with the plane of the half-ring coinciding with the y-z plane of the frame as shown in Fig. 1. The 


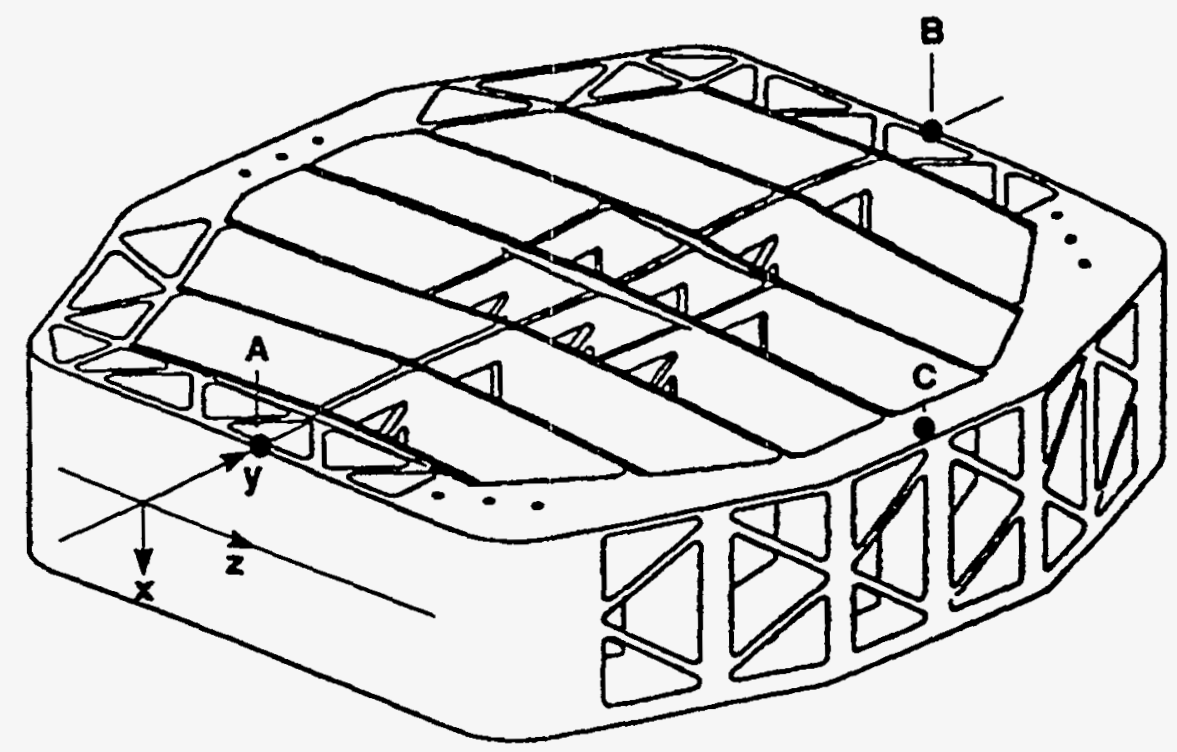

Figure 1. General view of support frame.

half-ring is supposed to be loaded under pseudo-static conditions involving in-plane as well as out-of-plane response. The nominal values of acceleration specified during the original design were 15 and $8 \mathrm{~g}$ 's for the out-of-plane and in-plane conditions respectively.

In order to, partially account for the additional portions of the material affecting mean radius of the half-ring, reference can be made to a sketch in Fig. 2. The indicated dimensions have been scaled from the appropriate drawings and should be sufficiently accurate for the approximate calculations.

The projected area of the half-ring (based on the top view, Fig. 1) prior to adding corner material shown in Fig. 2, is taken here as

$$
A_{i}=\frac{\pi}{2}\left(R_{o}^{2}-R_{i}^{2}\right)
$$

where, stating all dimensions in inches, we have

$$
\begin{aligned}
R_{0} & =15.25 \\
R_{i} & =15.25-2.06 \\
& =13.19
\end{aligned}
$$

and 


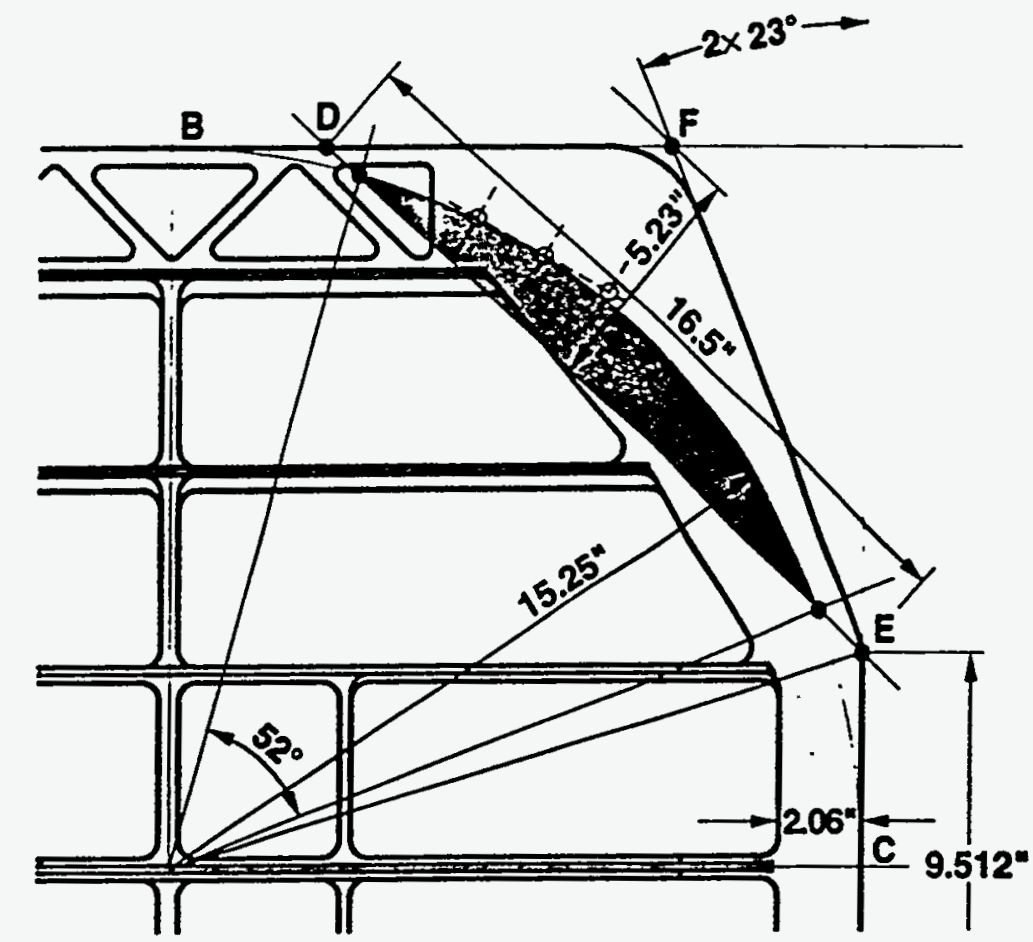

Figure 2. Dimensions affecting mean radius.

$$
\begin{aligned}
A_{i} & =\frac{\pi}{2}\left(15.25^{2}-13.19^{2}\right) \\
& =92.2 \text { in. }^{2}
\end{aligned}
$$

The corner areas, such as DFE, given in Fig. 2 should be corrected by subtracting the sector areas $\left(A_{\mathbf{g}}\right)$, shown as shaded.

$$
A_{s}=\frac{R_{0}^{2}}{2}(\phi-\sin \phi)
$$

The subtended angle $(\phi)$ is found from Fig. 2 to be $52^{\circ}$. Hence using Eq. (2), yields

$$
\begin{aligned}
A_{S} & =\frac{15.25^{2}}{2}(0.908-0.788) \\
& =13.95 \text { in. }^{2}
\end{aligned}
$$


The remaining corner area (using dimensions from Fig. 2) is

$$
\begin{aligned}
A_{c} & =0.5 \times 5.23 \times 16.5-13.95 \\
& =29.2 \text { in. }^{2}
\end{aligned}
$$

Then, the total projected area (including corners) is

$$
\begin{aligned}
A_{t} & =A_{i}+2 A_{c} \\
& =92.2+2 \times 29.2 \\
& =150.6 \mathrm{in}^{2}
\end{aligned}
$$

The new inner radius ( $r$ ) must now be smaller than $R_{i}$, so that we have

$$
A_{t}=\frac{\pi}{2}\left(R_{o}^{2}-r^{2}\right)
$$

Rearranging Eq. (3), gives

$$
r=0.56\left(\pi R_{o}^{2}-2 A_{t}\right)^{1 / 2}
$$

and, substituting

$$
\begin{aligned}
r & =0.56\left(\pi \times 15.25^{2}-2 \times 150.6\right)^{1 / 2} \\
& =116 \mathrm{in} .
\end{aligned}
$$

Hence the mean radius $(R)$ is

$$
\begin{aligned}
R & =(116+15.25) / 2 \\
& =13.4 \mathrm{in} .
\end{aligned}
$$

The outline of the equivalent ring (based on the top view) and the relevant new radii $(r)$ and $(R)$ magnitudes are given in Fig. 3. The general complexity of the frame with the moments of inertia about the $z$ and $x$ axes are shown in Fig. 4. The $I_{z x}$ and $I_{z z}$ values were obtained from the computer data bank at LLNL. Significant variations of rigidity in both planes can certainly be an open field for debate in any correlation of analytical results. 


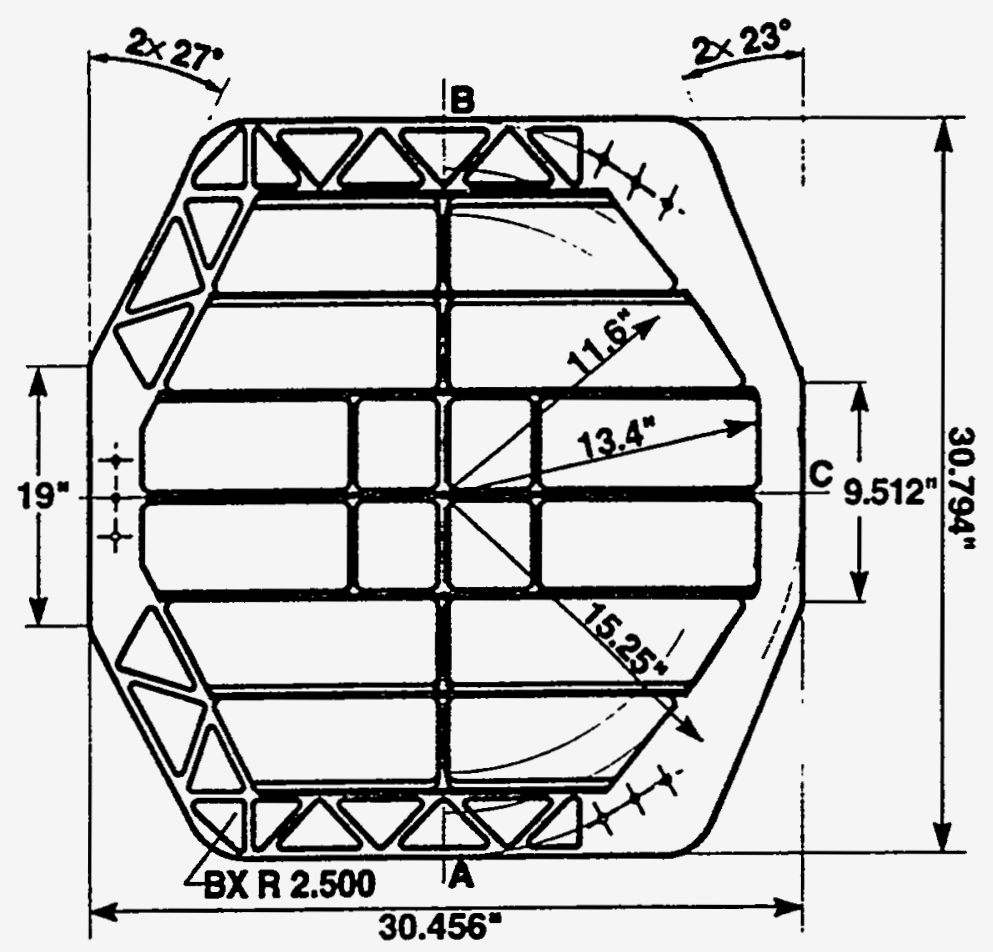

Figure 3. Outline of equivalent half-ring.

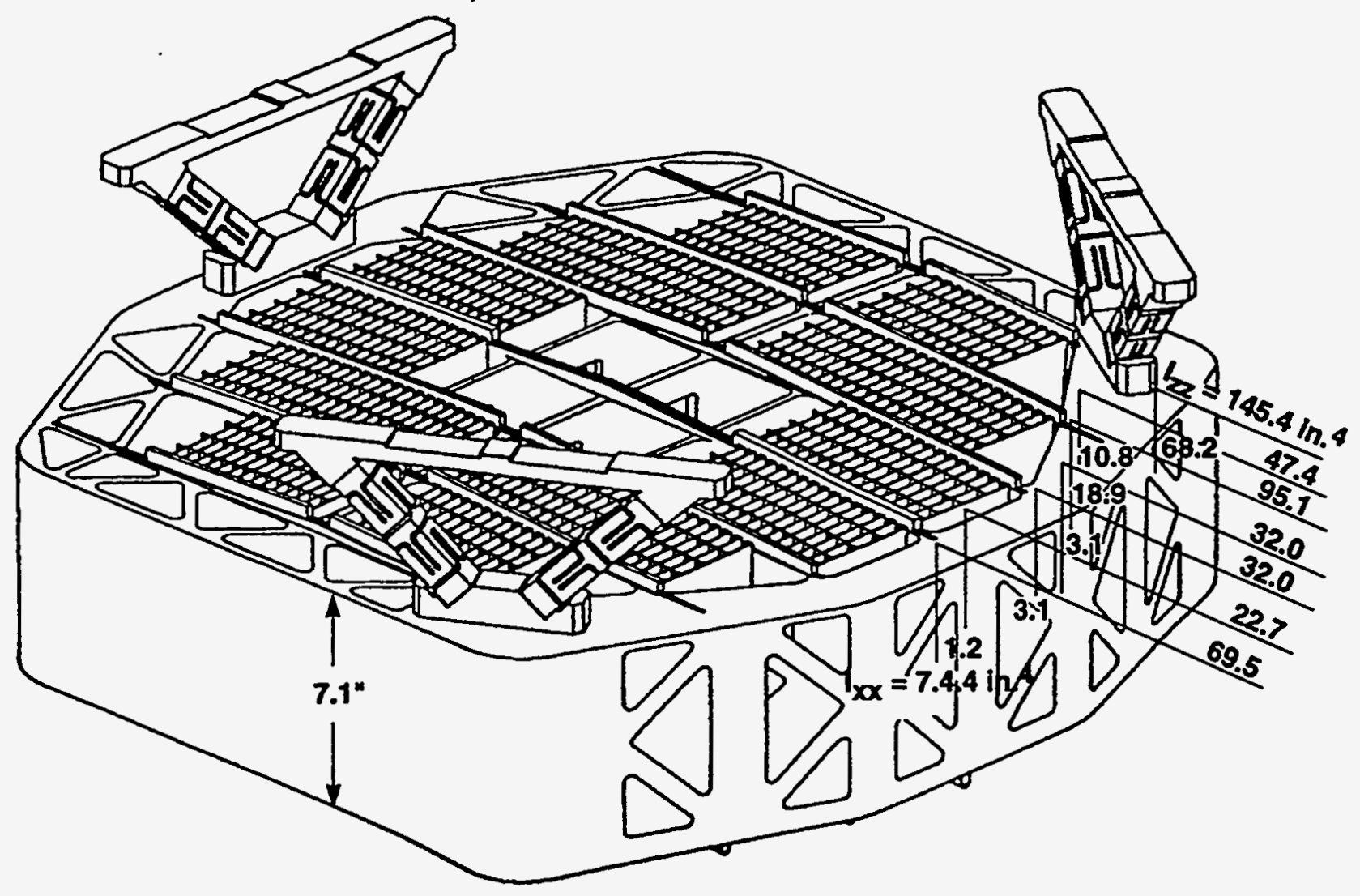

Figure 4. General complexity and second moments. 
The design formulas selected for the out-of-plane and in-plane behavior of the equivalent half-ring of the support frame have been developed from the classical theory of curved members. The specific formulas applicable to the case examined can be summed up as follows. The bending moment in terms of notation given in Fig. 5 is

$$
\mathrm{M}=\mathrm{qr}^{2}\left(\frac{\pi}{2} \sin \theta-1\right)
$$

The twisting moment can be written as

$$
\mathrm{T}=\mathrm{qR} \mathrm{R}^{2}\left[\theta+\frac{\pi}{2}(\cos \theta-1)\right]
$$

The fixing moment has a very simple form, at $\theta=0$.

$$
\mathrm{M}_{\mathrm{f}}=\mathrm{qR}^{2}
$$

The general expression for the deflection at any angle $(\theta)$ shown in Fig. 5 , is

$$
\begin{aligned}
\mathrm{Y} & =\frac{\mathrm{qR}}{8 \mathrm{EI}}\left\{2 \pi(\theta \cos \theta-\sin \theta)+\pi^{2}(1-\cos \theta)+\lambda[2 \pi(\theta \cos \theta-3 \sin \theta)\right. \\
& \left.\left.+\pi^{2}(1-\cos \theta)+4 \theta(\pi-\theta)\right]\right\}
\end{aligned}
$$

and the angle of twist can be obtained from

$$
\eta=\frac{\pi \mathrm{qR}^{3}}{8 \mathrm{EI}}(1+\lambda)\left[2 \sin \theta+(\pi-2 \theta) \cos \theta-\frac{8}{\pi}\right]
$$

The total weight of the "Beryllium 1-250" structure (including grating and rails, supports with damping and springs) is given as $66.4 \mathrm{~kg}$ (from XMM/RGA CDR, 1994, presentation by T. A. Decker).

The g-levels specified by the original design criteria include:

\section{$15 \mathrm{~g}$ vertical \\ $8 \mathrm{~g}$ lateral}

The purpose of this review is to search for the most conservative criteria obtained through computer modeling of peak accelerations and through back calculations in simplified models using closed-form solutions. 


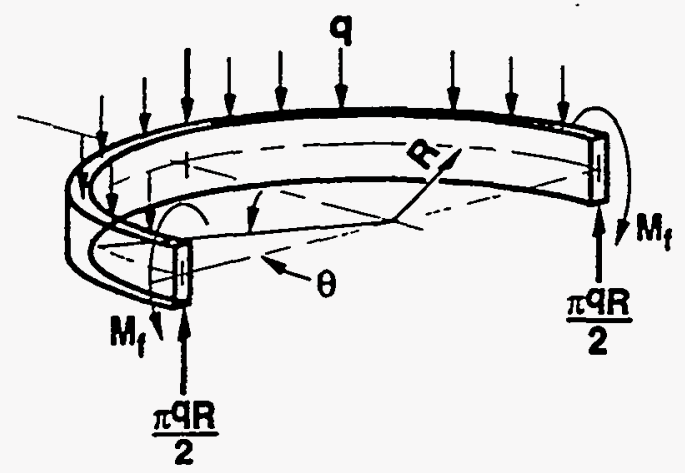

Figure 5. Half-ring equilibrium under transverse uniform loading.

The load per inch of the half-ring is

$$
\begin{aligned}
\mathrm{q} & =66.4 \times 2.24 / 2 \pi \times 13.4 \\
& =177 \mathrm{lb} / \mathrm{in} .
\end{aligned}
$$

For the original vertical criterion of $15 \mathrm{~g}$, the pseudo-static load per inch becomes

$$
\mathrm{q}=177 \times 15=26.6 \mathrm{lb} / \mathrm{in} .
$$

Then $\theta=0$ (using the absolute value only),

$$
\begin{aligned}
\mathrm{M}=\mathrm{M}_{\mathrm{f}} & =\mathrm{q} \mathrm{R}^{2} \\
& =26.6 \times 13.4^{2} \\
& =4,776 \mathrm{lb}-\mathrm{in} .
\end{aligned}
$$

Taking the minimum value of the moment of inertia from Fig. 4, and c equal to one half of the depth of the ring, we have

$$
\begin{aligned}
c & =7.1 / 2 \\
& =3.55 \mathrm{in} .
\end{aligned}
$$

and

$$
\begin{aligned}
Z & =I / c \\
& \left.=27 / 3.55 \quad \text { (using } I \cong \frac{32+22.7}{2}\right) \\
& =7.61 \mathrm{in}^{3} .
\end{aligned}
$$


The corresponding bending stress becomes

$$
\begin{aligned}
S_{b} & =M / Z \\
& =4,776 / 7.61 \\
& =628 \mathrm{psi}
\end{aligned}
$$

Before utilizing other aspects of the out-of-plane response of the half-ring, it is necessary to recall the parameter $(\lambda)$ which is defined as the ratio of the bending and torsional rigidities.

$$
\lambda=\frac{\mathrm{EI}}{\mathrm{GK}}
$$

Here

$$
\begin{aligned}
E & =\text { elastic modulus, } p s i \\
G & =\text { shear modulus of elasticity, psi } \\
I & =\text { moment of inertia, in }{ }^{4} \\
K & =\text { torsional shape factor }, \text { in }^{4}
\end{aligned}
$$

In turn, the shear modulus relates to the elastic modulus through the Poisson's ratio effect, using a conventional formula.

$$
\mathrm{G}=\mathrm{E} / 2(1+\gamma)
$$

where

$$
\gamma=\text { Poisson's ratio }
$$

The theoretical limits of this ratio include a maximum of 0.5 for a perfectly deformable material and zero for a perfectly brittle material. Poisson's ratio for beryllium is rather close to zero, and it is certainly lower than that for glass, plutonium, or concrete at the lower end of the spectrum. If it can be as low as 0.027 , then for all practical purposes, Eq. (12) simplifies to

$$
\mathrm{G} \cong \mathrm{E} / 2
$$


Hence, Eq. (11) is also made simpler to give

$$
\lambda=2 \mathrm{I} / \mathrm{K}
$$

The next task is to approximate the parameter $(\mathrm{K})$. The $(\mathrm{K})$ value was not taken from the computer data bank. The derivation of $(K)$ values can be unusually complex because the distribution of shear stresses across irregular sections is nonlinear. A rough approximation in this case will be obtained using the following argument.

Since (h) is given by $7.1 \mathrm{in}$., and the minimum value of $(\mathrm{I})$ is also known, taking for instance the average moment of inertia values from Fig. 4, gives

$$
\begin{aligned}
I & =\frac{32+22.7}{2} \\
& \equiv 27 \text { in. }^{4}
\end{aligned}
$$

From a standard formula, we have

$$
\frac{\mathrm{bh}^{3}}{12}=27
$$

where (b) and (h) terms normally represent width and depth of the rectangular crosssection. Solving for the width of the cross section, yields

$$
\begin{aligned}
b & =12 \times 27 / \mathrm{h}^{3} \\
& =324 / 7.1^{3} \\
& \cong 0.91 \mathrm{in} .
\end{aligned}
$$

In calculating the torsion parameters, the ratio of the longer to shorter side determines the constant for finding the torsional shape factor $(K)$. Note that in the case of torsion (b) and ( $t)$ are longer and shorter sides.

$$
\mathrm{K}=\mathrm{C}_{\mathrm{k}} \mathrm{bt}^{3}
$$

Hence for $b / t=7.1 / 0.91=7.8$, the constant $C_{k}=0.33$ is given in standard tables for a long and narrow rectangular cross section. We then have, from Eq. (15)

$$
\begin{aligned}
K & =0.33 \times 7.1 \times 0.91^{3} \\
& =1.78 \text { in. }^{4}
\end{aligned}
$$


and, from Eq. (14)

$$
\begin{aligned}
\lambda & =2 \times 27 / 1.78 \\
& =30.3
\end{aligned}
$$

The maximum shearing stress in torsion of an arbitrary cross section is

$$
\tau=T / K_{s}
$$

where $(\mathrm{T})$ is the twisting moment and $\left(\mathrm{K}_{\mathrm{S}}\right)$ defines the section modulus for torsion given by

$$
\mathrm{K}_{\mathrm{s}}=\mathrm{C}_{\mathrm{s}} \mathrm{bt}^{2}
$$

Since $(b / t)$ is as high as before, $C_{8}=0.33$, so that using Eq. (17), gives

$$
\begin{aligned}
\mathrm{K}_{\mathrm{s}} & =0.33 \times 7.1 \times 0.91^{2} \\
& =1.96 \mathrm{in}^{3}
\end{aligned}
$$

To find the maximum value of the twisting moment from Eq. (6) the first derivative $(d T / d \theta)$ is made equal to zero. Hence

$$
\frac{\mathrm{dT}}{\mathrm{d} \theta}=\mathrm{qR}^{2}\left(1-\frac{\pi}{2} \sin \theta\right)=0
$$

from which

$$
\sin \theta=2 / \pi
$$

and

$$
\theta \equiv 39.5 \mathrm{deg}
$$

Substituting this value in Eq. (6), we have

$$
\begin{aligned}
\mathrm{T} & =\mathrm{qR} \mathrm{R}^{2}[0.6894+1.5708(0.7716-1)] \\
& =0.33 \mathrm{qR}^{2}
\end{aligned}
$$


Therefore, from Eq. (16)

$$
\begin{aligned}
\tau & =0.33 \mathrm{qR}^{2} / 1.96 \\
& =0.169 \times 26.6 \times 13.4^{2} \\
& =807 \mathrm{psi}
\end{aligned}
$$

For the record, the maximum shearing stress in torsion for the case illustrated in Fig. 5 is

$$
\tau=0.33 \mathrm{qR}^{2} / \mathrm{K}_{\mathrm{s}}
$$

The next step is to obtain a simple formula for deflection of the half-ring, Fig. 5, from the general expression, Eq. ( 8 ) by assuming $\theta=\pi / 2$. Hence the terms in the large bracket become

$$
\begin{aligned}
2 \pi(0 & -1)+\pi^{2}(1-0)+\lambda\left[2 \pi(0-3)+\pi^{2}(1-0)+2 \pi\left(\pi-\frac{\pi}{2}\right)\right] \\
& =-2 \pi+\pi^{2}+\lambda\left[-6 \pi+\pi^{2}+\pi^{2}\right] \\
& =-2 \pi+\pi^{2}+30.3\left[2 \pi^{2}-6 \pi\right] \\
& =-6.2832+9.8696+598.0978-571.1415 \\
& =30.5427
\end{aligned}
$$

Therefore the formula for the specific $(\lambda)$ term, becomes

$$
\mathrm{Y}=3.82 \frac{\mathrm{qR}^{4}}{\mathrm{EI}}
$$

For other $(\lambda)$ values, a more general formula for the maximum out-of-plane deflection (that is at $\theta=\pi / 2$ ), can be taken as

$$
\mathrm{Y}=0.45(1+0.25 \lambda) \frac{\mathrm{qR}^{4}}{\mathrm{EI}}
$$


For the specific case at hand, Eq. (19) yields

$$
\begin{aligned}
Y & =3.82 \times 26.6 \times 13.4^{4} / 27 \times 44 \times 10^{6} \\
& =0.0028 \mathrm{in} . \quad(0.07 \mathrm{~mm})
\end{aligned}
$$

The dimensionless parameter $\left(\mathrm{YEL} / \mathrm{qR} \mathrm{R}^{4}\right)$ varies linearly with $(\lambda)$ which represents the ratio of flexural to torsional rigidity.

The angle of twist is given by Eq. (9). It can be shown that as the angle $(\theta)$ is varied between 0 and $\pi / 2$, the direction of rotation of the ring cross section changes. Hence, there must be a point at which $\eta=0$. This is equivalent to stating that

$$
2 \pi \sin \theta+\pi(\pi-2 \theta) \cos \theta-8=0
$$

Simple check of this equation shows that the cross section does not rotate at $\theta=45$ degrees.

The maximum angle of twist can be found at $\theta=0$. In order to obtain the appropriate formula, the terms in the square bracket of Eq. (9), reduce to

$$
\pi-\frac{8}{\pi}
$$

so that the required formula becomes

$$
\eta=\frac{\pi^{2}-8}{8}(1+\lambda) \frac{q R^{3}}{E I}
$$

For the case at hand, the angle of twist is

$$
\begin{aligned}
\eta & =\frac{\pi^{2}-8}{8} \times(1+30.3) \times 26.6 \times 13.4^{3} / 27 \times 44 \times 10^{6} \\
& =0.000394 \mathrm{rad}
\end{aligned}
$$

The angle of twist varies linearly with $(\lambda)$ as shown by Eq. (21).

\section{Sinking Support Model}

A portion of support frame shown in Fig. 6 was modeled as a half-ring under transverse uniform load in the foregoing section. The load was distributed along the circumference and the deflection was analyzed in terms of flexural and torsional rigidity deduced from the second moment data recorded by a computer during the initial phase of design. The computer modeling was based on the geometrical shape involving bays, 


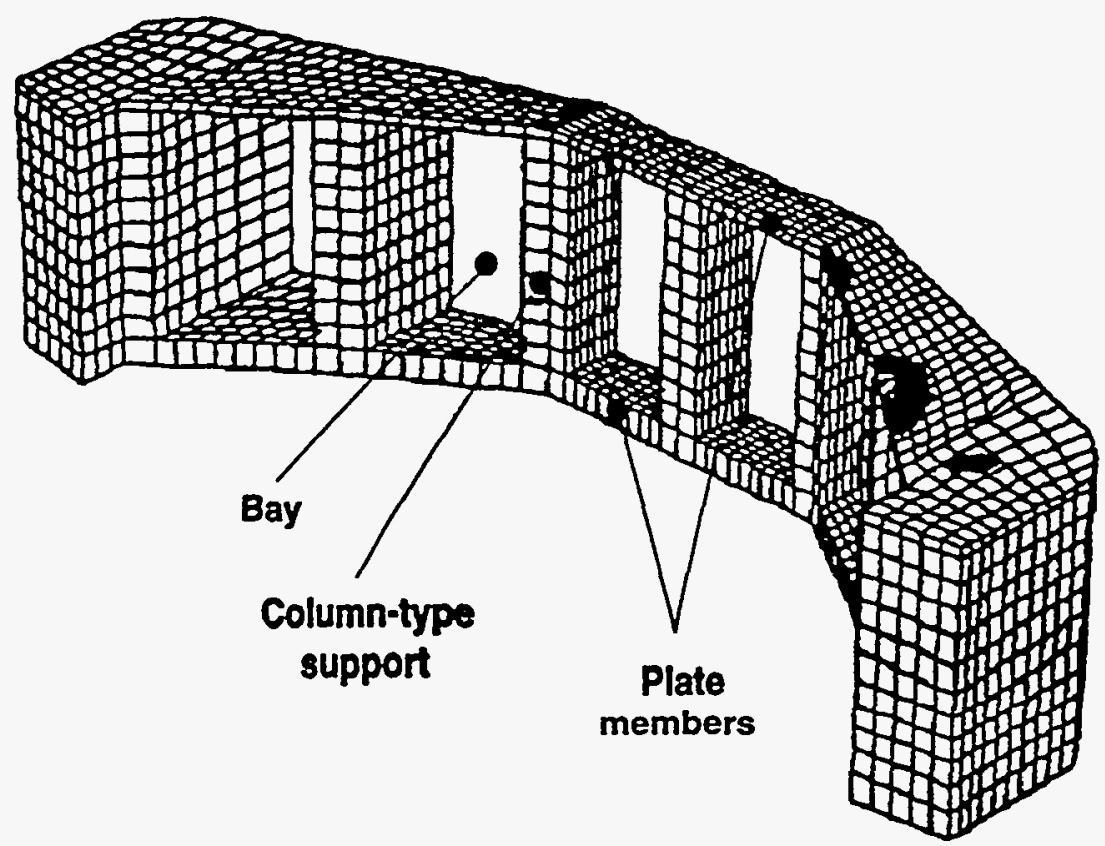

Figure 6. Part view of support frame.

supporting columns and plate members indicated in Figs. 6 and 7. We therefore have six individual bays bordered by heavy, column-like supports with top and bottom plate members constituting a continuous structure. Each bay then acting as an individual rectangular frame can be deformed and deflected downwards, say in the x-direction, according to the global coordinates given in Fig. 7.

The bays shown in Figs. 6 and 7 have thinner connecting plates at the top where the locally-higher stress fields are indicated in Fig. 7. The maximum computergenerated stress is $3180 \mathrm{psi}$ in an element designated as 4156.

The deformation mode of the plate members, assumed for the sinking support model, is sketched roughly in Fig. 8. Because of symmetry, the total downward deflection of the support frame can be taken as $Y_{t}=3 \mathrm{Y}$, where individual deflection $(\mathrm{Y})$ is modeled with the help of the, so called "double cantilever" or a "beam with sinking support" illustrated in Fig. 9. The corresponding formulas for this case of beam behavior, for the maximum moment and deflection, are

$$
\mathrm{M}_{\mathrm{o}}=\mathrm{WL} / 2
$$

and

$$
\mathrm{Y}=\frac{\mathrm{WL}^{3}}{12 \mathrm{EI}}
$$

The first issue concerning the model shown in Fig. 8 is the determination of loading (W) for the upper and lower plate members indicated in Figs. 6 and 7. This is done on 


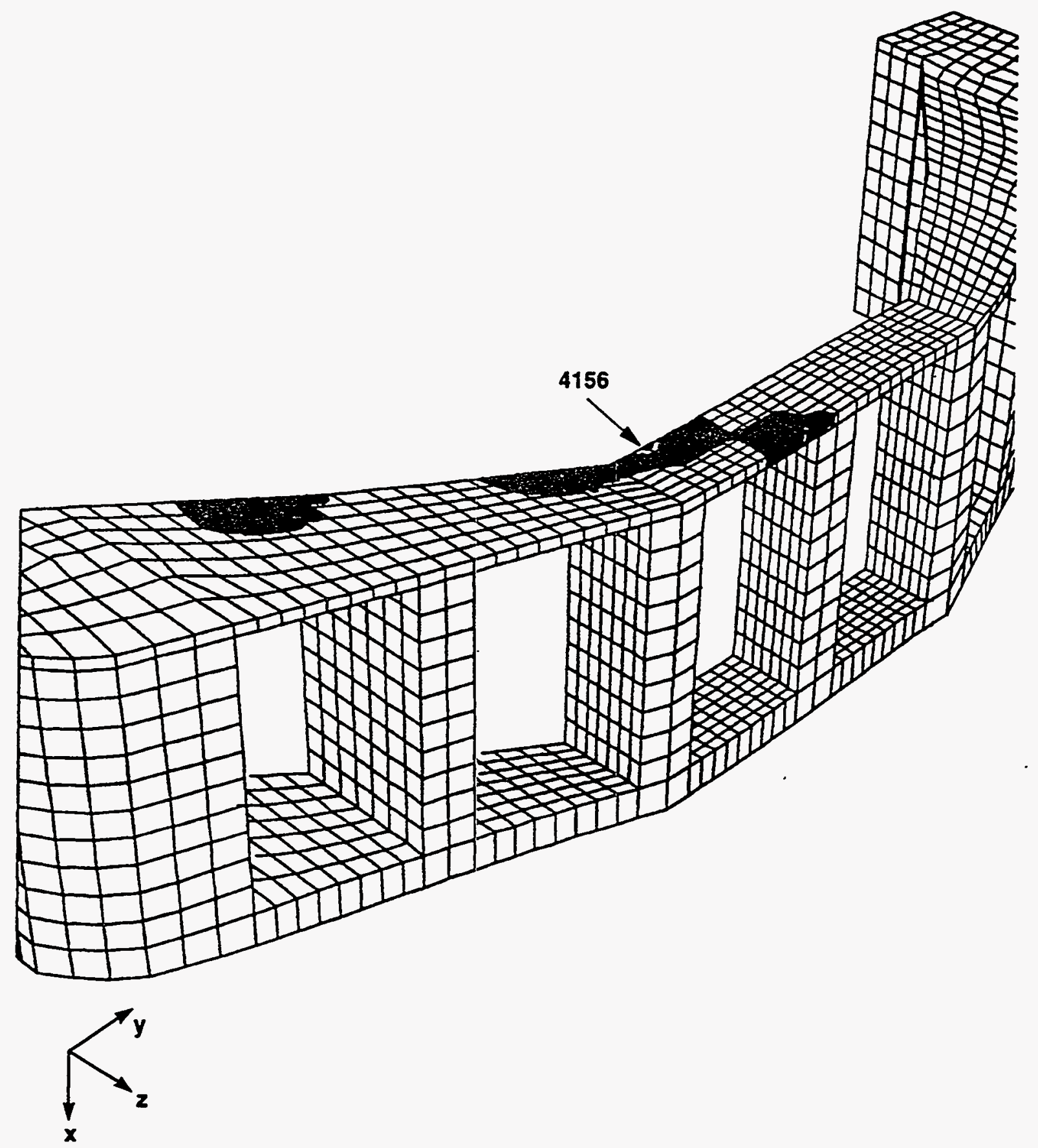

Figure 7. Computer mesh and stress fringes (after Gerhard).

the premise that the total load transmitted by the five column supports, ties the upper and lower plates so that the top and lower plates will experience the same displacement (Y). However, the loads carried by the plate members, and modeled as beams on sinking supports, will be different because of different bending rigidities. To characterize the various elements of the problem, assume the following notion

$$
\begin{aligned}
\mathrm{W}_{\mathrm{u}} & =\text { Load carried by upper plate } \\
\mathrm{W}_{1} & =\text { Load carried by lower plate } \\
\mathrm{I}_{\mathrm{u}} & =\text { Moment of inertia of upper plate } \\
\mathrm{I}_{1} & =\text { Moment of inertia of lower plate }
\end{aligned}
$$




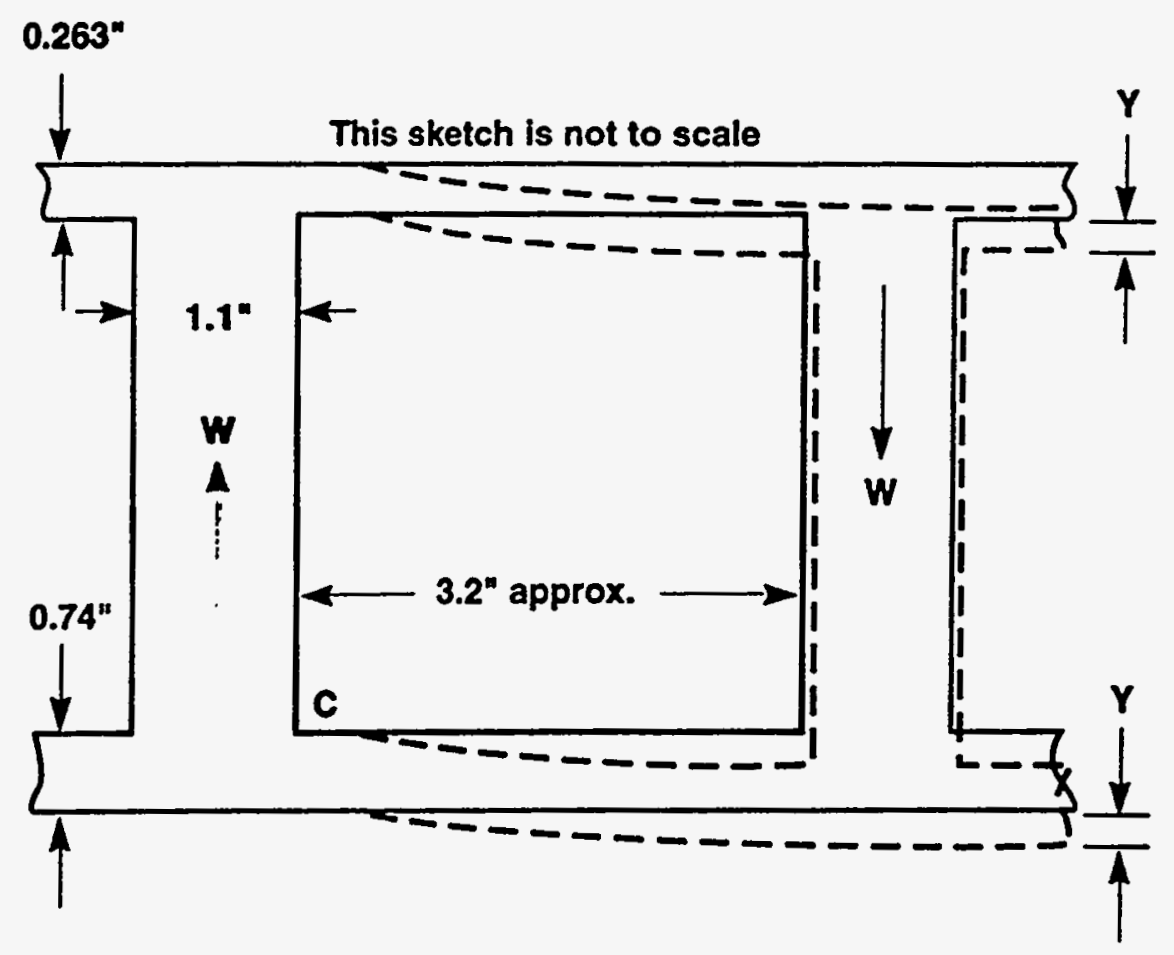

Figure 8. Assumed deformation mode.

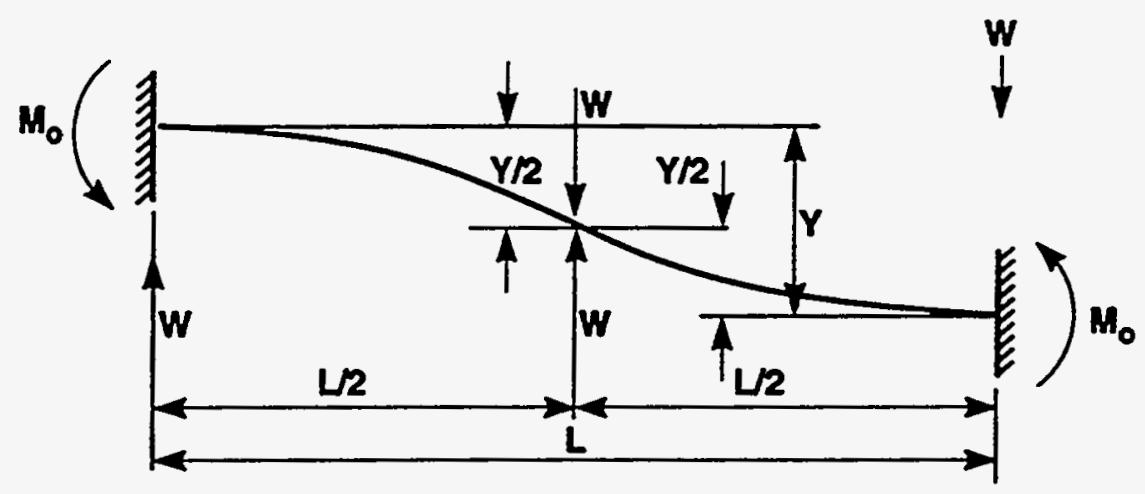

Figure 9. Double cantilever or a beam with sinking support. 
Therefore we can state three conditions

$$
\begin{aligned}
& \mathrm{Y}=\frac{\mathrm{W}_{\mathrm{u}} \mathrm{L}^{3}}{12 \mathrm{EI}_{\mathrm{u}}} \\
& \mathrm{Y}=\frac{\mathrm{W}_{1} \mathrm{~L}^{3}}{12 \mathrm{EI}_{1}}
\end{aligned}
$$

and

$$
\mathrm{W}=\mathrm{W}_{\mathrm{u}}+\mathrm{W}_{\mathrm{l}}
$$

The first two equations give

$$
\frac{W_{u}}{I_{u}}=\frac{W_{1}}{I_{l}}
$$

From Eq. (25)

$$
\mathrm{W}_{\mathrm{u}}=\mathrm{W}_{\mathrm{l}} \mathrm{I}_{\mathrm{u}} / \mathrm{I}_{\mathrm{l}}
$$

From Eq. (24)

$$
\mathrm{w}_{\mathrm{l}}=\mathrm{W}-\mathrm{w}_{\mathrm{u}}
$$

so that combining the foregoing relations, we have

$$
W_{u}=W\left(\frac{I_{u}}{I_{u}+I_{l}}\right)
$$

From Fig. 8, the upper and lower thicknesses, are

$$
t_{u}=0.263 \text { in } .
$$

and

$$
t_{1}=0.74 \text { in. }
$$


and the corresponding moments of inertia (using standard formulas) are

$$
\begin{aligned}
& I_{u}=\frac{b t_{u}^{3}}{12} \\
& I_{1}=\frac{b t_{1}^{3}}{12}
\end{aligned}
$$

so that

$$
\begin{aligned}
\frac{I_{u}}{I_{1}} & =\frac{1}{1+\left(\frac{t_{l}}{t_{u}}\right)^{3}} \\
& =\frac{1}{1+\left(\frac{0.74}{0.263}\right)^{3}}
\end{aligned}
$$

resulting in

$$
I_{u}=0.04 I_{1}
$$

Introducing this value into Eq. (26), gives

$$
\begin{aligned}
W_{u} & =\left(\frac{0.04 I_{1}}{0.04 I_{1}+I_{1}}\right) W \\
& =0.038 \mathrm{~W}
\end{aligned}
$$

Hence, for all practical purposes, the effect of upper plate member on the overall rigidity of the frame can be neglected. The total pseudo-static load is, as before, $2,230 \mathrm{lb}$, so that the load $(\mathrm{W})$ can be taken as

$$
0.5 \times 2,230 / 5=223 \mathrm{lb}
$$

Hence, using the assumption of $W_{t}=3 W$, and Eq. (23) written for the lower plate member (modeled as a beam), we have

$$
\mathrm{Y}=\frac{\mathrm{WL}^{3}}{4 \mathrm{EI}_{1}}
$$


where

$$
\mathrm{I}_{\mathrm{l}}=\frac{\mathrm{bt} \mathrm{t}^{3}}{12}
$$

The dimension (b) in Eq. (28) is taken as 2.06 in., as in the analysis of a half-ring. Substituting the relevant dimensions in Eqs. (28) and (27) gives

$$
\begin{aligned}
I_{1} & =\frac{2.06 \times 0.74^{3}}{12} \\
& =0.0696 \mathrm{in}^{4}
\end{aligned}
$$

and

$$
\begin{aligned}
Y & =\frac{223 \times 3.2^{3}}{4 \times 44 \times 10^{6} \times 0.0696} \\
& =0.0006 \mathrm{in} .
\end{aligned}
$$

It is not surprising that this value is smaller than the "half-ring model" value of 0.0028 . Only a part of the ring was involved in the "sinking support" version of the calculation, and no account was made of the curvature. It may then be of interest to find a rough order of magnitude for the correction. Let us assume that such a correction depends on two elements, including the effect of length and curvature.

The cumulative length of the "sinking support" beams is taken on the basis of Fig. 8, as a direct summation of straight portions.

$$
3 \times 4.3=12.9 \text { in. }
$$

The corresponding curved portion length may be assumed to be equivalent to one quarter of the circumference. This is conservative.

$$
\begin{aligned}
\pi R / 2 & =1.5708 \times 13.4 \\
& =21.05 \mathrm{in} .
\end{aligned}
$$

Hence the first part of the correction comes from the ratio.

$$
21.05 / 12.9=1.63
$$


The second part can be derived from a comparison of straight and curved members such as those given in Fig. 10. The angle subtended by the curved member is obtained from $L=12.9$ and $R=13.4$ in., using circular arc chord and radius.

$$
\begin{aligned}
0.5 \times 12.9 & =13.4 \sin (\phi / 2) \\
0.481 & =\sin (\phi / 2)
\end{aligned}
$$

from which

$$
\phi=57.4 \mathrm{deg}
$$

The relevant design formulas are as follows.

$$
Y_{1}=\frac{q R^{4}}{E I}\left(\lambda B_{7}-B_{3}\right)
$$

and

$$
\mathrm{Y}_{2}=\frac{\mathrm{qL}}{8 \mathrm{EI}}
$$

where

$$
\mathrm{B}_{7}=\left(2 \phi^{2}-\cos 2 \phi-4 \phi \sin \phi+1\right) / 4
$$

and

$$
B_{3}=(4 \cos \phi-\cos 2 \phi-3) / 4
$$

Since $(\phi)$ for this case is close to one radian, Eq. (31) simplifies to

$$
\mathrm{B}_{7}=0.75-0.25 \cos 2 \phi-\sin \phi
$$

Substituting the values of

$$
\begin{aligned}
\sin \phi & =0.8425 \\
\cos \phi & =0.5388 \\
\cos 2 \phi & =-0.4195
\end{aligned}
$$



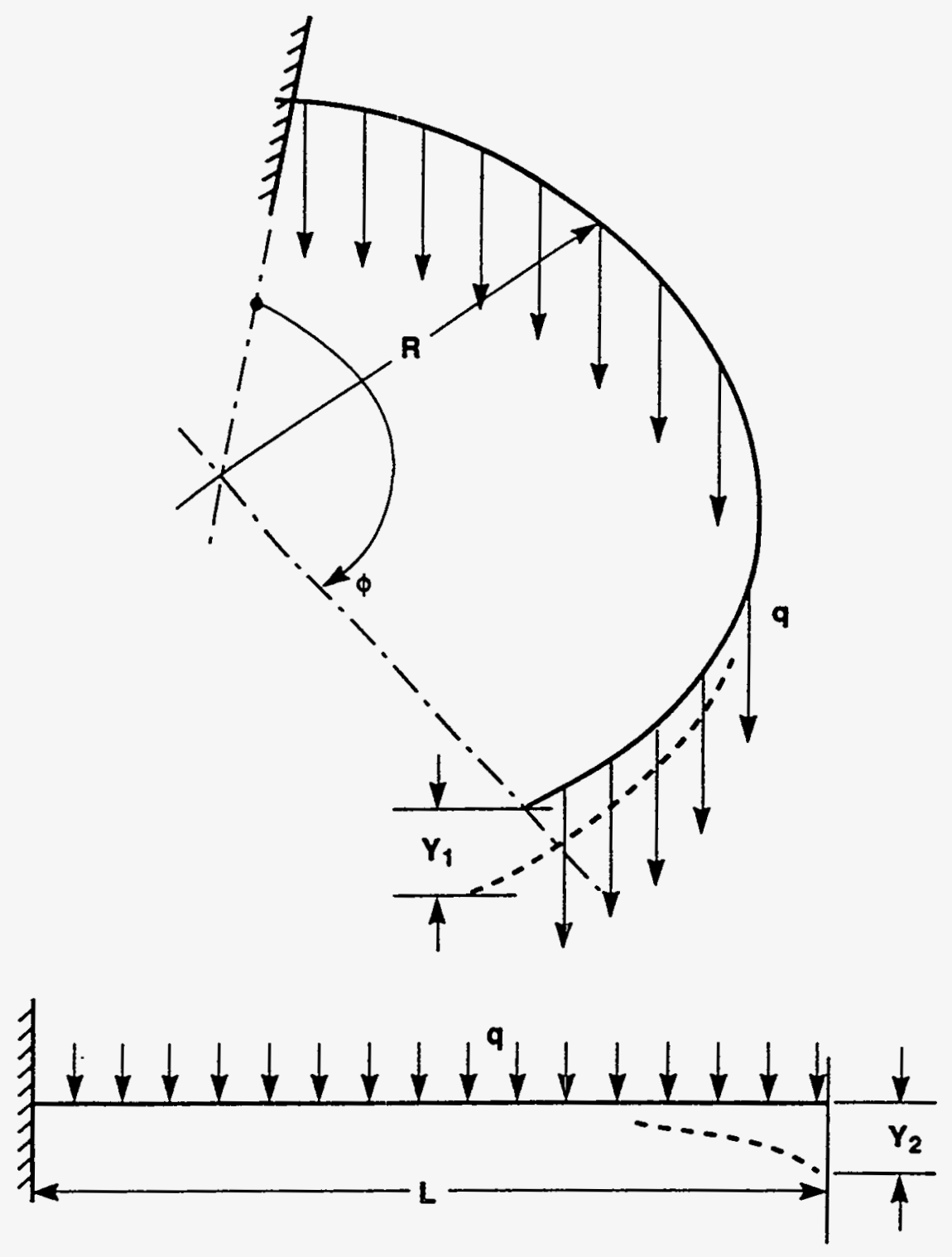

Figure 10. Straight and curved member notation.

we get

$$
\begin{aligned}
\mathrm{B}_{7} & =0.75-0.25 \times(-0.4195)-0.8425 \\
& =0.0124 \\
\mathrm{~B}_{3} & =0.5388-0.25 \times(-0.4195)-0.75 \\
& =-0.1063
\end{aligned}
$$

Hence

$$
Y_{1}=\frac{q R^{4}}{E I}(0.0124 \lambda+0.1063)
$$


The value of $(\lambda)$ which is the ratio of flexural to torsional rigidity for the "sinking support" model is approximated here as

$$
\begin{aligned}
I & =2.06 \times 7.1^{3} / 12 \\
& =61.4 \text { in. }^{4}
\end{aligned}
$$

The torsional shape factor for the same section can be obtained from standard tables or charts for the ratio of

$$
7.1 / 2.06=3.5
$$

This gives a constant $\left(C_{k}\right)$ equal to 0.275 . The torsional shape factor is found from Eq. (15).

$$
\begin{aligned}
K & =0.275 \times 7.1 \times 2.06^{3} \\
& =17.07
\end{aligned}
$$

Hence $(\lambda)$ parameter can be calculated from Eq. (14).

$$
\begin{aligned}
\lambda & =\frac{2 \times 61.4}{17.07} \\
& =7.2
\end{aligned}
$$

The deflection formula, Eq. (34), is simplified further by substituting the $(\lambda)$ value to give

$$
\mathrm{Y}_{1}=0.196 \frac{\mathrm{qR}}{\mathrm{EI}}
$$

The second part of the correction, accounting for the effect of curvature, follows from Eqs. (35) and (30).

$$
\begin{aligned}
\frac{Y_{1}}{Y_{2}} & =\frac{0.196 \mathrm{R}^{4}}{0.125 \mathrm{~L}^{4}} \\
& =1.568(13.4 / 12.9)^{4} \\
& =1.83
\end{aligned}
$$


Therefore, the corrected deflection for the "sinking support" model is

$$
\begin{aligned}
Y & =1.63 \times 1.83 \times 0.0006 \\
& =0.0018 \mathrm{in.} \quad(0.045 \mathrm{~mm})
\end{aligned}
$$

Although the corrections used are, admittedly, rough, the agreement is sufficiently encouraging, for a structural system of great complexity. Considering significant differences between the approaches a better correlation of the two results $(0.0028$ and 0.0018 ) could only be regarded as fortuitous.

The local bending stress at such a point as (C) in Fig. 8, can be estimated from a standard formula.

$$
\mathrm{S}_{\mathrm{b}}=\frac{3 \mathrm{WL}}{\mathrm{bt_{1 } ^ { 2 }}}
$$

Hence substituting the appropriate numerical values gives the following result for the lower plate member.

$$
\begin{aligned}
\mathrm{S}_{\mathrm{b}} & =\frac{3 \times 223 \times 3.2}{2.06 \times 0.74^{2}} \\
& =1898 \mathrm{psi} \quad(13.1 \mathrm{MPa})
\end{aligned}
$$

For the upper plate member which is significantly thinner $\left(t_{\mathrm{u}}\right)$ but which also carries very small load (according to the "sinking support" model), Eq. (36) yields

$$
\begin{aligned}
S_{b} & =\frac{3 \times 0.04 \times 223 \times 3.2}{2.06 \times 0.263^{2}} \\
& =601 \mathrm{psi} \quad(4.1 \mathrm{MPa})
\end{aligned}
$$

Not until a correction can be made for a high-peak, short-pulse g-level, the stress values approach such numbers as those indicated in Fig. 7. Taking a g-level of 28 would bring the foregoing plate stresses to

$$
1898 \times 28 / 15=3,543 \mathrm{psi} \quad(24.4 \mathrm{MPa})
$$

and

$$
601 \times 28 / 15=1,122 \mathrm{psi} \quad(7.7 \mathrm{MPa})
$$


The latter result applies to several locations (Fig. 7) where the thin upper plate member connects to the solid portion of the frame or the column-like support.

\section{Other Deflection Models}

The purpose of this section is to make a reference to other design methodology outside the half-ring (out-of-plane) and sinking support techniques. The basic idea in evaluating a computer generated results in critical areas is to postulate a conservative approach to the problem utilizing conventional theories and formulas.

The development of the half-ring approach was conservative from the start because it assumed the placement of the two supports consistent with the $\mathrm{ABC} \operatorname{arc}\left(180^{\circ}\right.$, Fig. 3) although the entire frame ring had three supports defining accurately the plane of the structure. The next model then can be an approximately-circular ring resting on three supports and carrying a transverse uniform load. The design equation for the circular ring carrying uniformly distributed load for $(n)$ number of supports is

$$
\mathrm{Y}=\frac{\pi \mathrm{qR}^{4}}{\mathrm{n}^{4}}\left(\frac{\mathrm{D}_{5}}{\mathrm{EI}}+\frac{\mathrm{D}_{6}}{\mathrm{GK}}\right)
$$

Substitute the following numerical values obtained previously in developing the "halfring" model.

$$
\begin{aligned}
\mathrm{q} & =26.6 \mathrm{lb} / \mathrm{in} . \\
\mathrm{R} & =13.4 \mathrm{in} . \\
\mathrm{E} & =44 \times 10^{6} \mathrm{psi} \\
\mathrm{G} & =0.5 \mathrm{E} \mathrm{psi} \\
\mathrm{I} & =27 \mathrm{in} .{ }^{4} \\
\mathrm{~K} & =1.78 \mathrm{in}^{4}
\end{aligned}
$$

then

$$
\begin{aligned}
& \mathrm{Y}=\frac{\pi \times 26.6 \times 13.4^{4}}{\mathrm{n}^{4}}\left(\frac{D_{5}}{27 \mathrm{E}}+\frac{\mathrm{D}_{6}}{0.5 \mathrm{E} \times 1.78}\right) \\
& \mathrm{Y}=\frac{0.002267 \mathrm{D}_{5}+0.068764 \mathrm{D}_{6}}{\mathrm{n}^{4}}
\end{aligned}
$$


The bending moment for the multiple supports of the ring is

$$
\mathrm{M}=\frac{\mathrm{qR}^{2} \mathrm{D}_{2}}{12 \mathrm{n}^{2}}
$$

The corresponding twisting moment is

$$
\mathrm{T}=\frac{\pi \mathrm{qR} \mathrm{R}^{2}}{2}
$$

The force and displacement factors for Eqs. (37), (38), (39), and (40) are given in the following table.

Table 1. Force and displacement factors.

\begin{tabular}{ccccc}
\hline $\mathrm{n}$ & $\mathrm{D}_{2}$ & $\mathrm{D}_{4}$ & $\mathrm{D}_{\mathbf{5}}$ & $\mathrm{D}_{\mathbf{6}}$ \\
\hline 2 & 47.9909 & 0.20710 & 2.2832 & 0.56640 \\
3 & 427030 & 0.05157 & 1.6305 & 0.17950 \\
4 & 41.2038 & 0.02060 & 1.4676 & 0.09072 \\
5 & 40.5567 & 0.01031 & 1.4006 & 0.05518 \\
6 & 40.2174 & 0.00588 & 1.3659 & 0.03740 \\
\hline
\end{tabular}

From Eq. (39), using two supports, that is $n=2$

$$
\begin{aligned}
\mathrm{M} & =\frac{26.6 \times 13.4^{2} \times 47.9909}{12 \times 4} \\
& =4776 \mathrm{lb}-\mathrm{in} .
\end{aligned}
$$

and taking $\mathrm{F}=7.61 \mathrm{in}^{3}$, as before

$$
\mathrm{S}_{\mathrm{b}}=4776 / 7.61=628 \mathrm{psi}
$$

The twisting moment follows from Eq. (40), as

$$
\begin{aligned}
\mathrm{T} & =\pi \times 26.6 \times 13.4^{2} \times 0.2071 / 2 \\
& =1554 \mathrm{lb}-\mathrm{in} .
\end{aligned}
$$


and using the section modulus for torsion $\left(\mathrm{K}_{\S}\right)$ as before

$$
\begin{aligned}
\tau & =1554 / 1.96 \\
& =793 \mathrm{psi}
\end{aligned}
$$

The three parameters $(\mathrm{M}),(\mathrm{T})$, and $(\mathrm{Y})$ can now be calculated with the help of the factors summarized in Table 1. After introducing the numerical data, we get

$$
S_{b}=52.3 D_{2} / n^{2}
$$

and

$$
\tau=7503 \mathrm{D}_{4}
$$

Hence using Eqs. (38), (41), and (42), the results based on the multiple-support model can be compiled in Table 2.

Table 2. Multiple-support design values.

\begin{tabular}{cccc}
\hline \hline $\mathbf{n}$ & $\mathbf{S}_{\mathbf{b}_{\text {pgi }}}$ & $\tau_{\text {psi }}$ & $\mathbf{Y}_{\text {in. }}$ \\
\hline 2 & 628 & 793 & 0.002819 \\
3 & 248 & 387 & 0.000207 \\
4 & 135 & 155 & 0.000040 \\
5 & 85 & 7 & 0.000012 \\
\hline
\end{tabular}

It may be of interest to note that the stresses and deflections calculated for the "half-ring" and the "multiple support" models for $n=2$, are identical. Hence the two approaches to the out-of-plane problem using here the theories of the elastic strain energy and the differential equations are consistent. The case of $n=3$ (three supports shown in Fig. 11), also follows from Table 2.

The design formula for another quick check of the support frame rigidity comes from the theory of pin-jointed circular arches under uniform in-plane loading. This formula was found to be useful in analysis of the compressor casing for a jet engine under in-flight inertia loading of the commercial jet liner in the early 1950s. The basic model geometry and notation are shown in Fig. 12. The horizontal thrust is equal to $(\mathrm{qR} / 2)$ where $(\mathrm{q})$ denotes weight of the curved member per inch of circumference. One half of the support frame subjected to side loading can be represented by the pinjointed arched structure given in Fig. 12. 


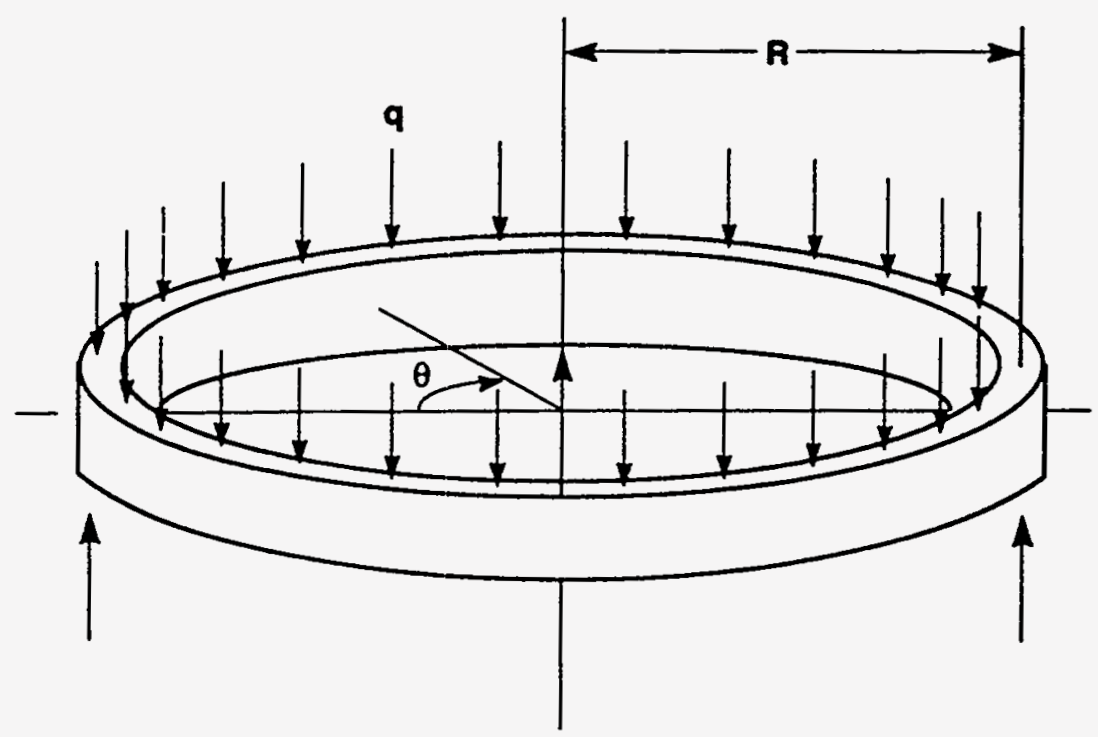

Figure 11. Three point support ring model.

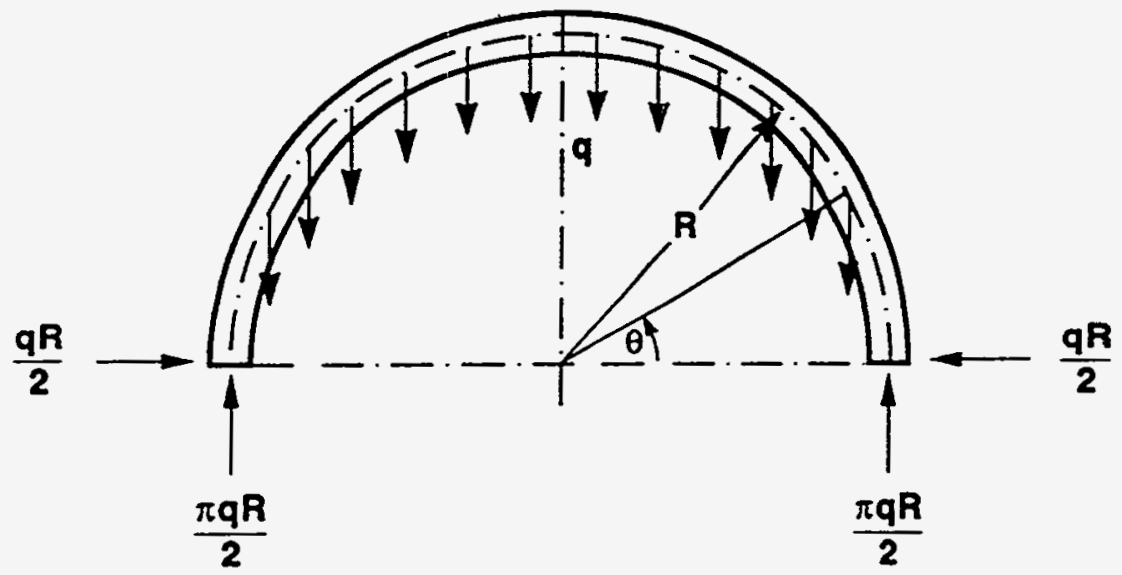

Figure 12. Pin-jointed semicircular arch under uniform vertical loading.

The bending moment at any section defined by $\theta$ is

$$
M=0.5 q R^{2}(\pi-\pi \cos \theta-3 \sin \theta+2 \theta \cos \theta)
$$

At

$$
\begin{aligned}
\theta & =\pi / 2 \\
\mathrm{M} & =0.5 q \mathrm{R}^{2}(\pi-3)
\end{aligned}
$$


or

$$
\mathrm{M}=0.071 \mathrm{qR}^{2}
$$

Selecting the minimum moment of inertia from Fig. 4, the required section modulus can be taken as

$$
\begin{aligned}
Z & =1.2 / 0.5 \times 2.06 \\
& =1.17 \text { in. }^{3}
\end{aligned}
$$

Hence the bending stress (under conservative assumptions) is

$$
\begin{aligned}
S_{b} & =\frac{0.071 \times 13.4^{2} q}{1.17} \\
& =10.9 q
\end{aligned}
$$

Using 8g's to determine the pseudo-static loading, gives

$$
\begin{aligned}
q & =0.5 \times 66.4 \times 2.24 \times 8 / p \times 13.4 \\
& =14.1 \mathrm{lb} / \mathrm{in} .
\end{aligned}
$$

and

$$
\begin{aligned}
S_{b} & =10.9 \times 14.1 \\
& =154 \mathrm{psi} \quad(1.06 \mathrm{MPa})
\end{aligned}
$$

The maximum, in-plane, deflection is given by

$$
\mathrm{Y}=0.0135 \mathrm{qR}^{4} / \mathrm{EI}
$$

Therefore

$$
\begin{aligned}
Y & =0.0135 \times 14.1 \times 13.4^{4} / 12 \times 44 \times 10^{6} \\
& =0.00012 \mathrm{in} . \quad(0.003 \mathrm{~mm})
\end{aligned}
$$

Comparative checks would not be complete without the simplest model such as a straight beam, shown in Fig. 13. The length can be taken from Fig. 3 equal to 30.8 in. 


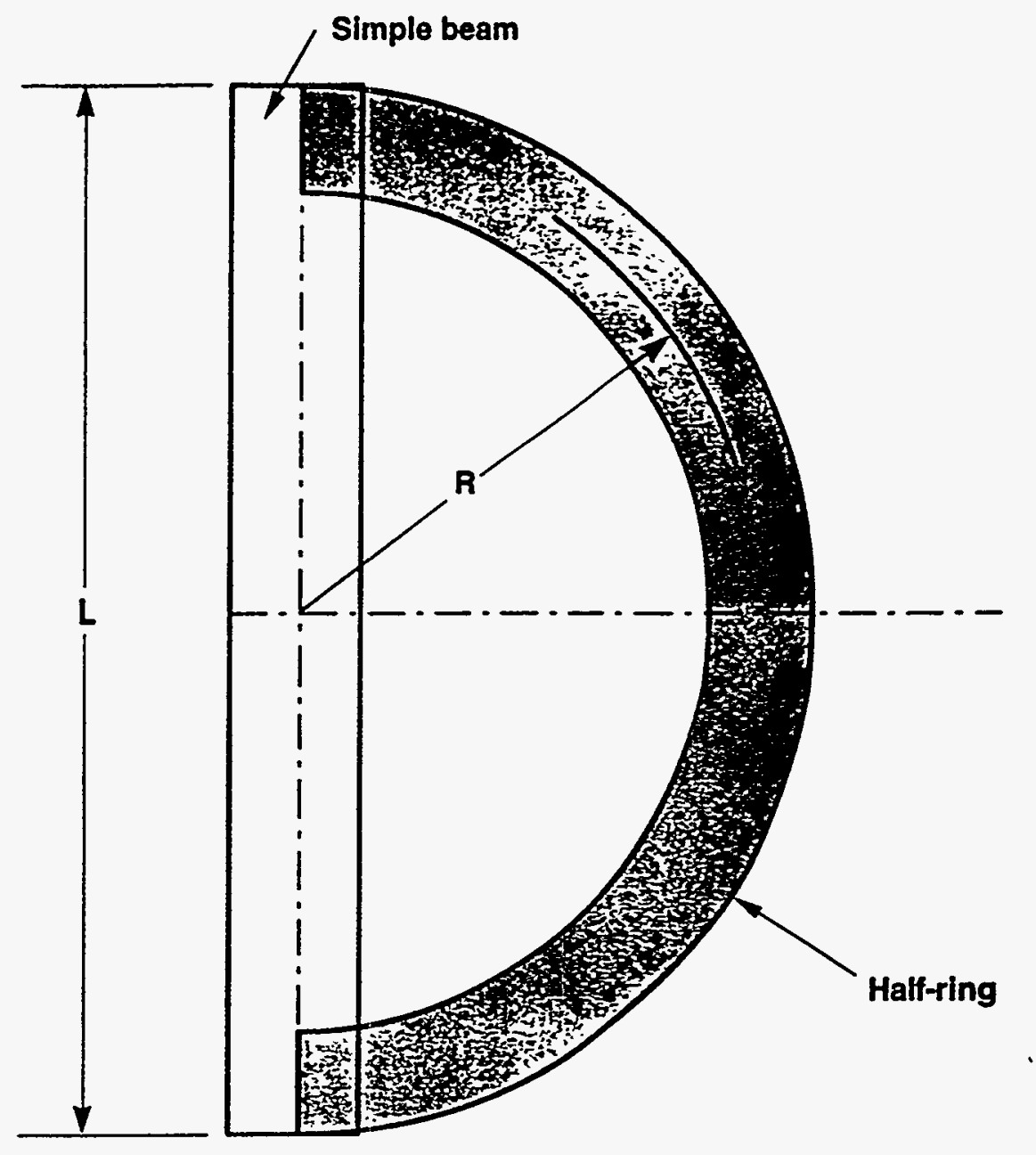

Figure 13. Beam and ring models.

For a simply supported beam carrying uniformly distributed load along the full length, the maximum bending moment is

$$
\mathrm{M}=\mathrm{qL}^{2} / 8
$$

The corresponding maximum deflection is

$$
\mathrm{Y}=\frac{5 \mathrm{qL}^{4}}{384 \mathrm{EI}}
$$


Taking the total pseudo-static load for finding (q), gives

$$
\begin{aligned}
\mathrm{q} & =66.4 \times 2.24 \times 15 / 30.8 \\
& =72.4 \mathrm{lb}-\mathrm{in} . \\
\mathbf{M} & =72.4 \times 30.8^{2} / 8 \\
& =8585 \mathrm{lb}-\text { in. }
\end{aligned}
$$

The section modulus calculated previously for the out-of-plane loading still applies. Hence the beam bending stress is

$$
\begin{aligned}
S_{b} & =8585 / 7.61 \\
& =1128 \mathrm{psi} \quad(7.78 \mathrm{MPa})
\end{aligned}
$$

The deflection (using $I=27$ in. ${ }^{4}$ ) follows from Eq. (47).

$$
\begin{aligned}
Y & =\frac{5 \times 72.4 \times 30.8^{4}}{384 \times 27 \times 44 \times 10^{6}} \\
& =0.00071 \mathrm{in} .
\end{aligned}
$$

The length correction may be taken as

$$
13.4 \pi / 30.8=1.37
$$

A conservative second correction (that is the effect of curvature) may be taken as 1.83 , derived previously in connection with the "sinking support" model. Hence the result corrected for the simple beam model becomes:

$$
\begin{aligned}
Y & =0.00071 \times 1.37 \times 1.83 \\
& =0.00178 \text { in. } \quad(0.045 \mathrm{~mm})
\end{aligned}
$$

\section{Strength of Plate Corners}

Computer generated stresses are found at the edges such as those illustrated in Fig. 14. The maximum local stress obtained from a computer run by Gerhard was 3,582 psi. A more detailed plate corner is shown in Fig. 15.

The approach to any strength checking of corners created by plate intersections (by machining) is attempted on the premise that the corners are sufficiently roundedoff to avoid stress concentrations in tension or bending. Traditionally, corners are 


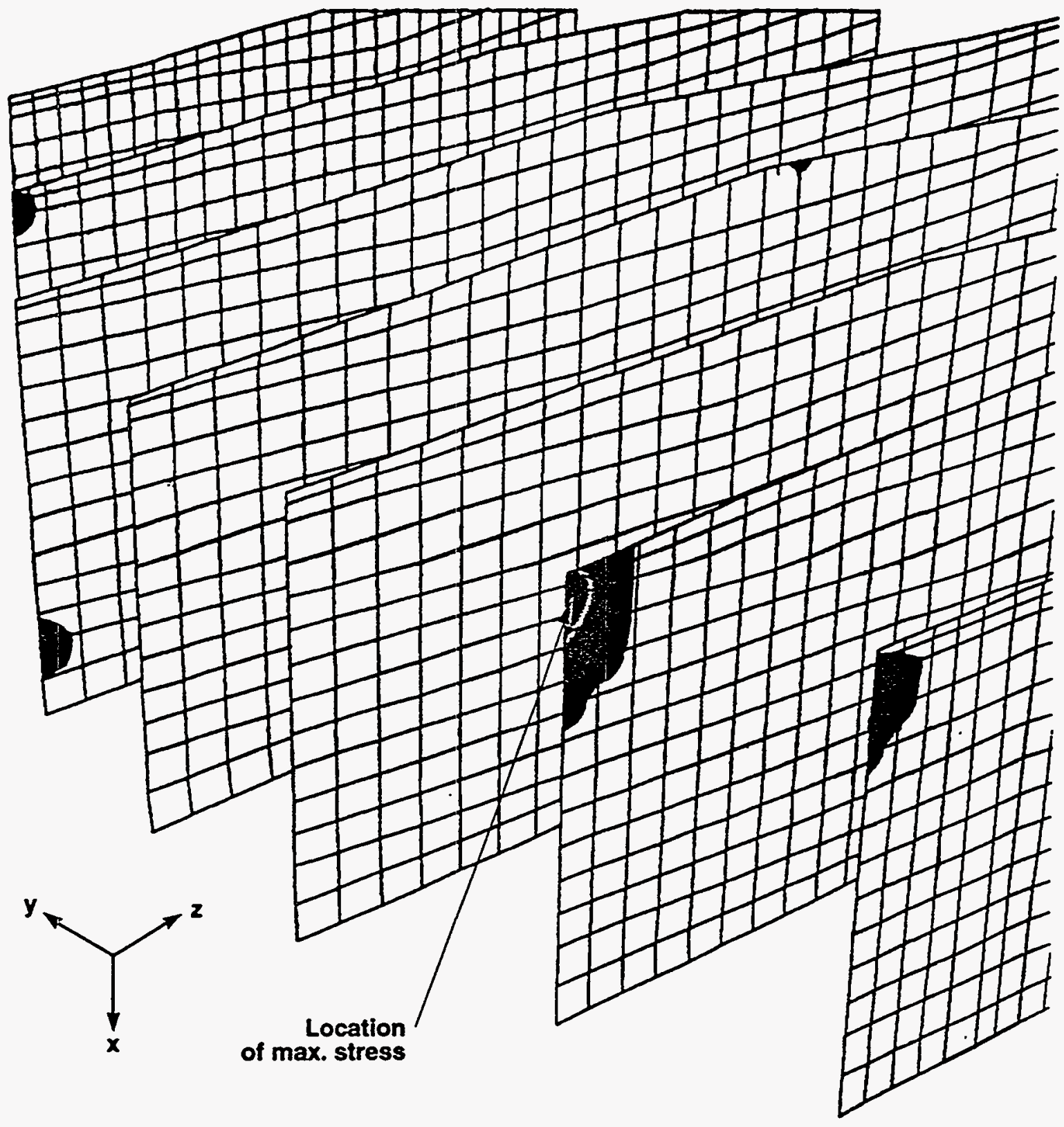

Figure 14. Stresses at plate edges.

looked upon as the sources of crack initiation and the creation of high stresses to drive the cracks. The corners showing small radii of curvature are particularly sensitive to high stresses, low ductility, and dynamic loads.

The purpose of this calculation is to look for a potential mode of deformation of a plate which, at least theoretically, can explain the order of stresses found in computer studies. The goal is then to postulate a credible model of plate behavior. The problem is of course that the loads generated in a dynamic environment (vibration) are difficult to define and next to impossible to measure. It is therefore necessary to fall back on simplified formulas and fundamentals of solid mechanics in order to get some idea of the physical problem at hand. 


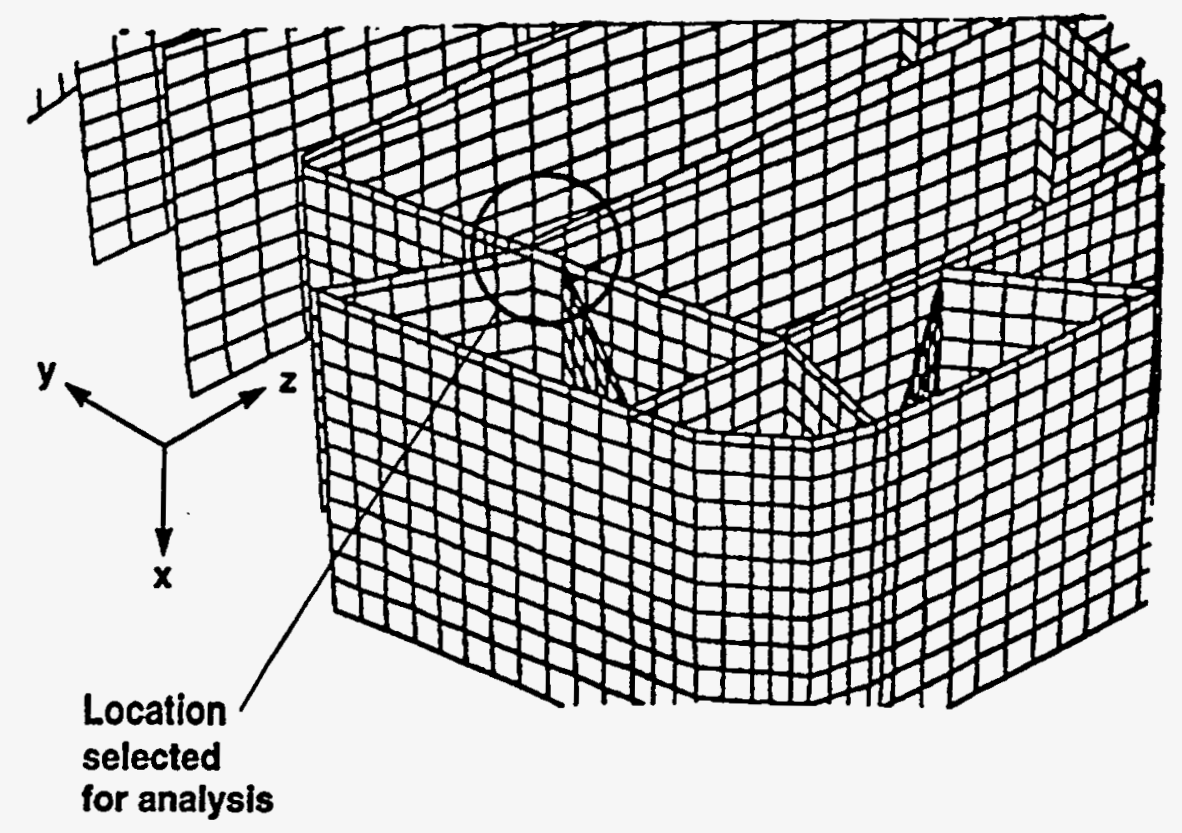

Figure 15. Detail of plate comer.

If with the best tools of closed-form nature the order of magnitude of the critical stresses cannot be approached then the most likely conclusion to be reached is that the computer-generated solution is conservative.

One possible mode is to assume that at some instant of a complex vibrational motion one plate edge at a point such as $B$, has moved in relation to point $A$ in the $y-z$ plane (global coordinates, Figs. 14 and 15), with the resultant mode of deformation shown by interrupted lines in Fig. 16. Hence the plate 7.1 in. wide and 4.25 in. long behaves as a wide beam. Under these conditions the term (E) should be replaced by $\left(\mathrm{E} / 1-\gamma^{2}\right)$ where $(\gamma)$ is Poisson's ratio. This effect is practically nonexistent because $(\gamma)$ is a small number.

The most conservative assumption, consistent with Fig. 16 is when the effect of the missing panel along the edge ( $B$ to $C$ ) is represented as the load per inch ( $q$ ) deforming the plate member ABCD.

It appears that there are, at least, two ways of looking at this problem. In one approach the total inertia force of one panel creates edge loading at some high peak value of $(g)$ such as 28 . While the exact $(\mathrm{g})$ value of a sharp peak may well be subject to debate, it is a good starting point for looking at the deformation mode sketched in Fig. 16.

The other possibility is to back-calculate the value of $(q)$ from the maximum stress indicated in Fig. 14. Both cases will now be examined in some detail.

The inertia load of a single panel with reference to the notation in Fig. 16 (assuming equal size of adjoining plates), is

$\mathrm{W}=7.1 \mathrm{q}$ 


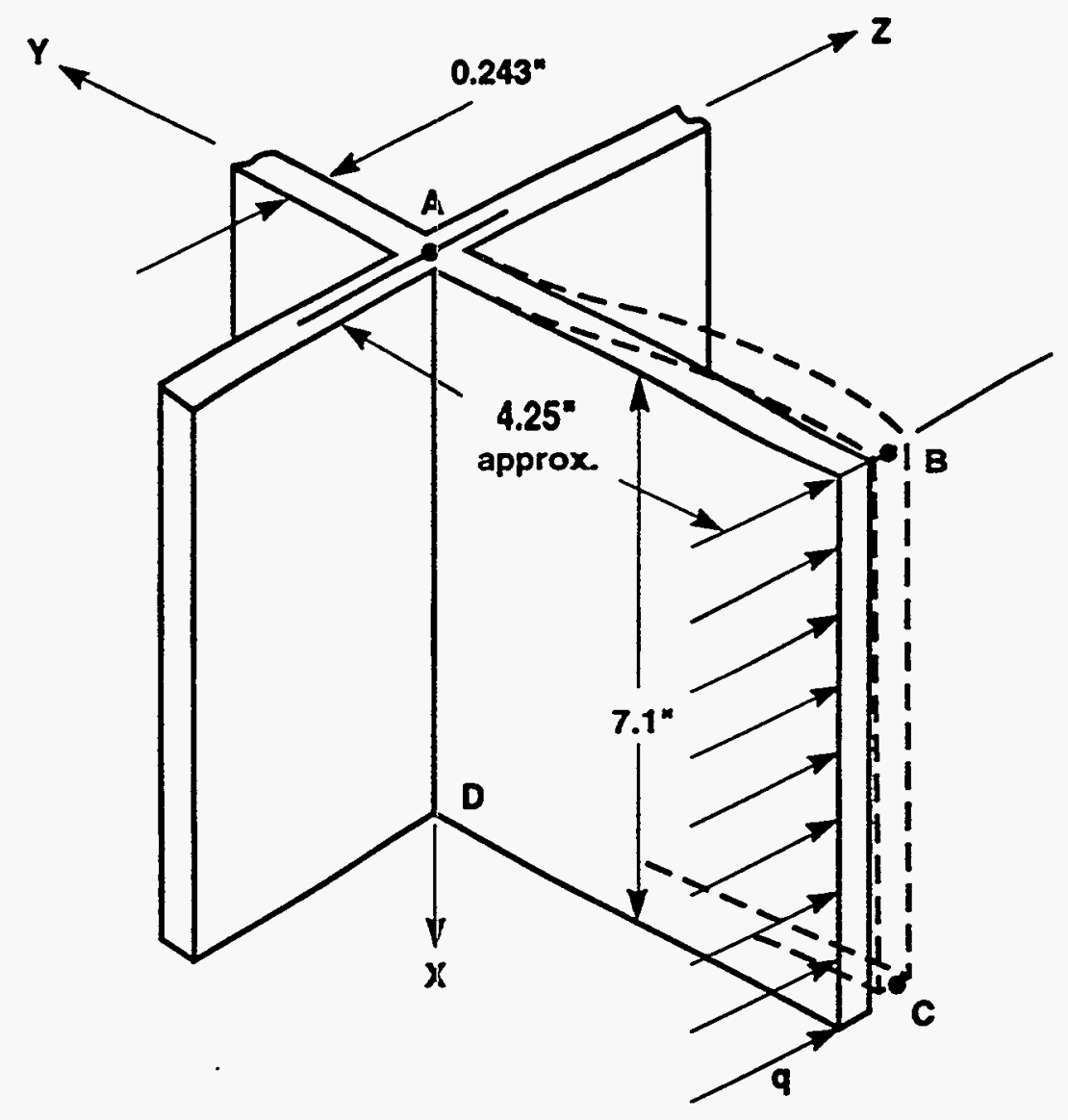

Figure 16. Deformation mode (assumed).

or

$$
\begin{aligned}
\mathrm{W} & =4.25 \times 7.1 \times 0.243 \times 28 \times 0.067 \\
& =13.8 \mathrm{lb}
\end{aligned}
$$

The moment of inertia is

$$
\begin{aligned}
I & =7.1 \times 0.243^{3} / 12 \\
& =0.00849 \mathrm{in}^{4}
\end{aligned}
$$

The corresponding section modulus follows as

$$
\begin{aligned}
\mathrm{Z} & =0.00849 / 0.5 \times 0.243 \\
& =0.07 \mathrm{in}^{3}
\end{aligned}
$$


Assuming next that the slopes at the edges $\mathrm{AD}$ and $\mathrm{BC}$ are both zero (built-in conditions) Eqs. (22) and (23) apply. Hence, for $\mathrm{L}=4.25$ in., we get

$$
\begin{aligned}
\mathrm{M}_{\mathrm{o}} & =13.8 \times 4.25 / 2 \\
& =29.3 \mathrm{lb}-\mathrm{in} .
\end{aligned}
$$

and

$$
\begin{aligned}
\mathrm{S}_{\mathrm{b}} & =\mathrm{M}_{0} / \mathrm{Z} \\
& =29.3 / 0.07 \\
& =419 \mathrm{psi} \quad(2.9 \mathrm{MPa})
\end{aligned}
$$

Also, the deflection from Eq. (23), is

$$
\begin{aligned}
Y & =\frac{13.8 \times 4.25^{3}}{12 \times 44 \times 10^{6} \times 0.00849} \\
& =0.00024 \mathrm{in} . \quad(0.006 \mathrm{~mm})
\end{aligned}
$$

For a spring-mass model in a single degree of freedom the natural frequency for the elastic beam behavior is

$$
f=\frac{3.1}{\left(\delta_{s t}\right)^{1 / 2}}
$$

So that

$$
\begin{aligned}
f & =3.1 /(0.00024)^{1 / 2} \\
& =200 \mathrm{~Hz}
\end{aligned}
$$

In allowing the local stress of 3,582 psi (Fig. 14) to be active along the entire length of the edge $A D$ (Fig. 16), a conservative estimate of the unit load (q) can be made using the following elementary transformation.

$$
\begin{aligned}
S_{b} & =M_{0} / Z \\
& =\frac{W L}{2 Z} \\
& =q L^{2} / 2 Z
\end{aligned}
$$


where

$$
\begin{aligned}
\mathrm{L} & =4.25 \mathrm{in} . \\
\mathrm{Z} & =0.07 \mathrm{in}^{3} \\
\mathrm{~S}_{\mathrm{b}} & =3,582 \mathrm{psi}
\end{aligned}
$$

Hence

$$
\begin{aligned}
\mathrm{q} & =2 Z \mathrm{~S}_{\mathrm{b}} / \mathrm{L}^{2} \\
& =2 \times 0.07 \times 3,582 / 4.25^{2} \\
& =27.8 \mathrm{lb} / \mathrm{in} .
\end{aligned}
$$

The total theoretical load on the plate edge would have to be

$$
\begin{aligned}
W & =7.1 \times 27.8 \\
& =197.4 \mathrm{lb}
\end{aligned}
$$

and the corresponding number of g's becomes

$197.4 / 4.25 \times 7.1 \times 0.243 \times 0.067=402$

The deflection increases to

$$
\frac{197.4}{13.8} \times 0.00024=0.0034 \text { in }
$$

and the natural frequency drops to

$$
\begin{aligned}
f & =\frac{3.1}{(0.0034)^{1 / 2}} \\
& =53 \mathrm{~Hz}
\end{aligned}
$$

These numbers suggest that the maximum stress shown in Fig. 14 is likely to be conservative. It appears rather difficult to justify the level of the applied g's indicated by the foregoing results, and it is hard to accept a considerable increase in the amplitude of vibration in otherwise rigid support frame.

The next check is concerned with the elastic stability of the plate member having the general proportions shown in Fig. 16 and the loading condition illustrated in Fig. 17. 

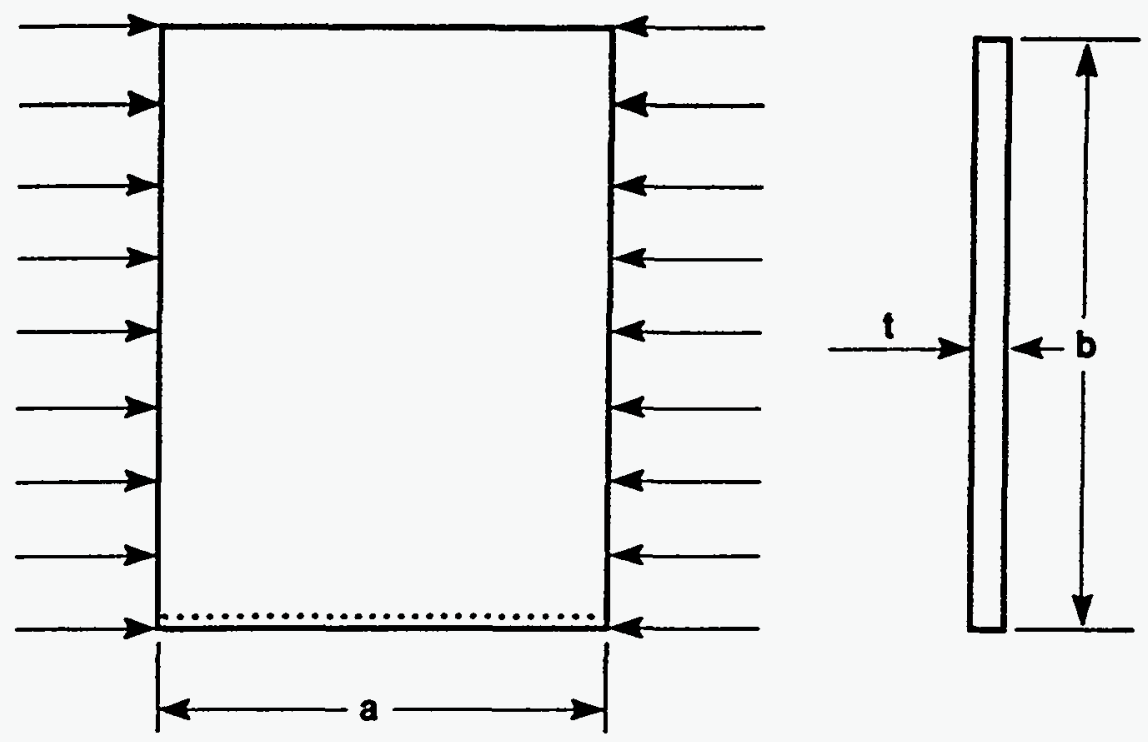

Figure 17. Assumed loading in buckding.

Here we have a plate having (b) sides simply supported, one (a) side simply supported and the top edge (a) free. The general expression for the critical buckling stress is

$$
S_{C R}=\frac{K^{*} E}{\left(1-\gamma^{2}\right)}\left(\frac{t}{b}\right)^{2}
$$

where $\left(\mathrm{K}^{*}\right)$ is the conventional buckling factor dependent on the $\mathrm{a} / \mathrm{b}$ ratio. The values of this factor are available in the standard sources for a large number of loading and support conditions. Here Eq. (49) represents a realistic but conservative case. Using notation from Fig. 17, and dimensions from Fig. 16, we have

$$
\begin{aligned}
\mathrm{a} / \mathrm{b} & =4.25 / 7.1 \\
& =0.6
\end{aligned}
$$

This ratio gives $\mathrm{K}^{*}=3.6$, so that for a small value of Poisson's ratio, Eq. (49), indicates

$$
\begin{aligned}
\mathrm{S}_{\mathrm{CR}} & =3.6 \times 44 \times 10^{6}(0.243 / 7.1)^{2} \\
& =185,546 \mathrm{psi} \quad(1,280 \mathrm{MPa})
\end{aligned}
$$

The critical stress is very high proving that there is certainly no problem with the elastic stability of the plate member examined. The torsional response of the plate of the same dimensions can be checked out with the help of Eqs. (15) and (17). In addition, the following simple expression for the shear stress in torsion of a rectangular cross section can be used in design. 


$$
\tau=\frac{\eta \mathrm{GK}}{\mathrm{LK}_{\mathrm{s}}}
$$

Note that in dealing with $(\mathrm{K})$ and $\left(\mathrm{K}_{\mathrm{s}}\right)$ parameters, the plate thickness in this report is denoted by $(t)$. Also the term (K) in Eq. (15) should not be confused with ( $\left.K^{*}\right)$ in Eq. (49). There is often a chance for errors in the symbols where numerous formulas are involved.

Where long and narrow rectangular cross sections are involved (with $\mathrm{b} / \mathrm{t}$ ratios higher than about 8) the ratio $\mathrm{K} / \mathrm{K}_{\mathbf{8}}$ is simplified so that the design formula for the torsional stress becomes

$$
\tau=\eta \mathrm{Gt} / \mathrm{L}
$$

In this formula $(\eta)$ is the angle of twist, $(L)$ is the length of the individual panel (such as 3.2" from Fig. 8), ( $t$ ) is panel thickness ( $0.263^{\prime \prime}$ in Fig. 8), and (G) is the shear modulus of elasticity. Assuming that three sets of the panels are involved in the twist action (halfring model, Fig. 6), the angle of twist for an individual panel may be taken as

$$
\begin{aligned}
\eta & =0.00039 / 3 \\
& =0.00013 \mathrm{rad}
\end{aligned}
$$

With the very small value of Poisson's ratio for beryllium, the shear modulus follows from Eq. (12).

$$
\begin{aligned}
\mathrm{G} & =0.5 \mathrm{E} \\
& =22 \times 10^{6} \mathrm{psi}
\end{aligned}
$$

Hence, using Eq. (51) and the dimensions from Fig. 8, yields

$$
\begin{aligned}
\tau & =0.00013 \times 22 \times 10^{6} \times 0.263 / 3.2 \\
& =235 \mathrm{psi} \quad(1.6 \mathrm{MPa})
\end{aligned}
$$

The next area for a brief review, relates to local and corner stresses such as those shown in. Fig. 18. The range of stress values in this case, as described by Gerhard, is between 2,000 and $3,000 \mathrm{psi}$, acting on a "window type frame" structure. The general mode of deformation is similar to that indicated in Fig. 16. The area of the support frame under discussion is also shown in Fig. 19, marked as location (2) and selected in consultation with Decker. 


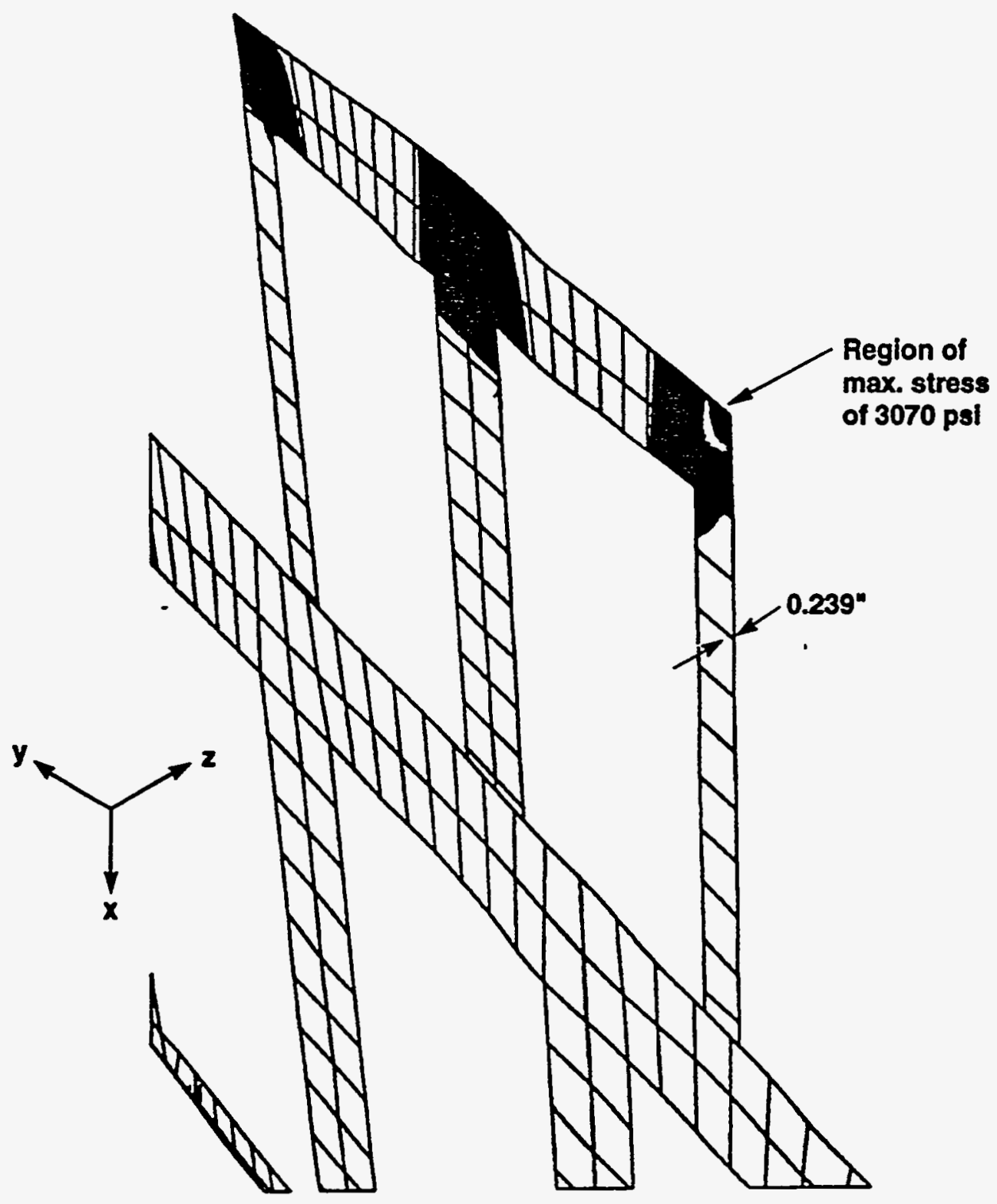

Figure 18. Typical corner stress field. 


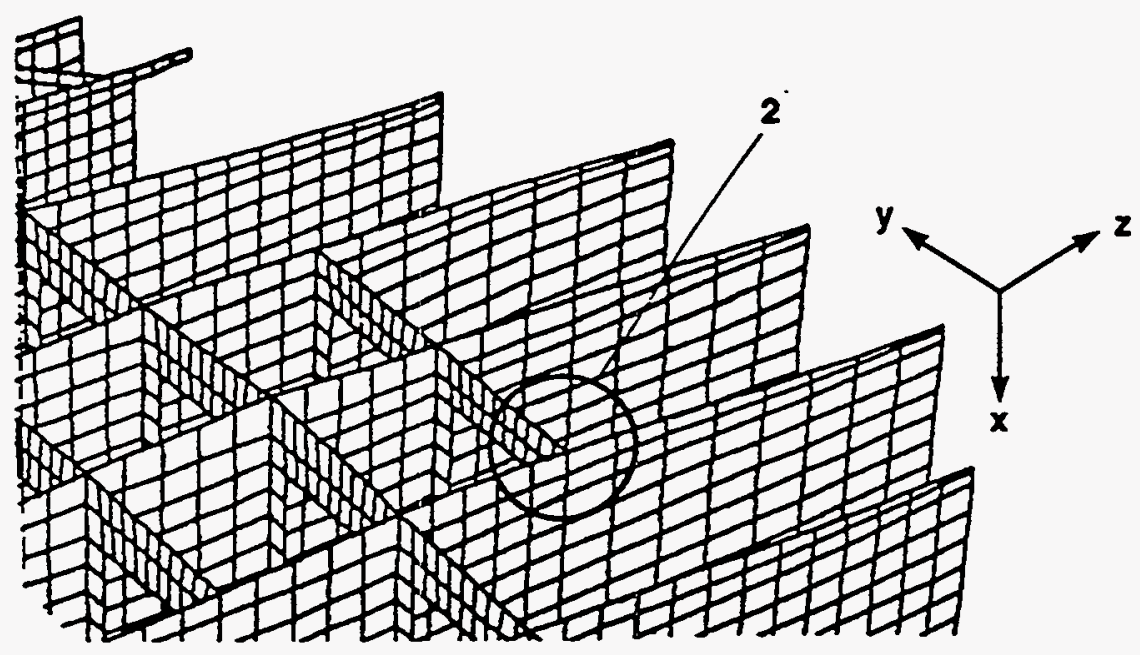

Figure 19. Location of critical area.

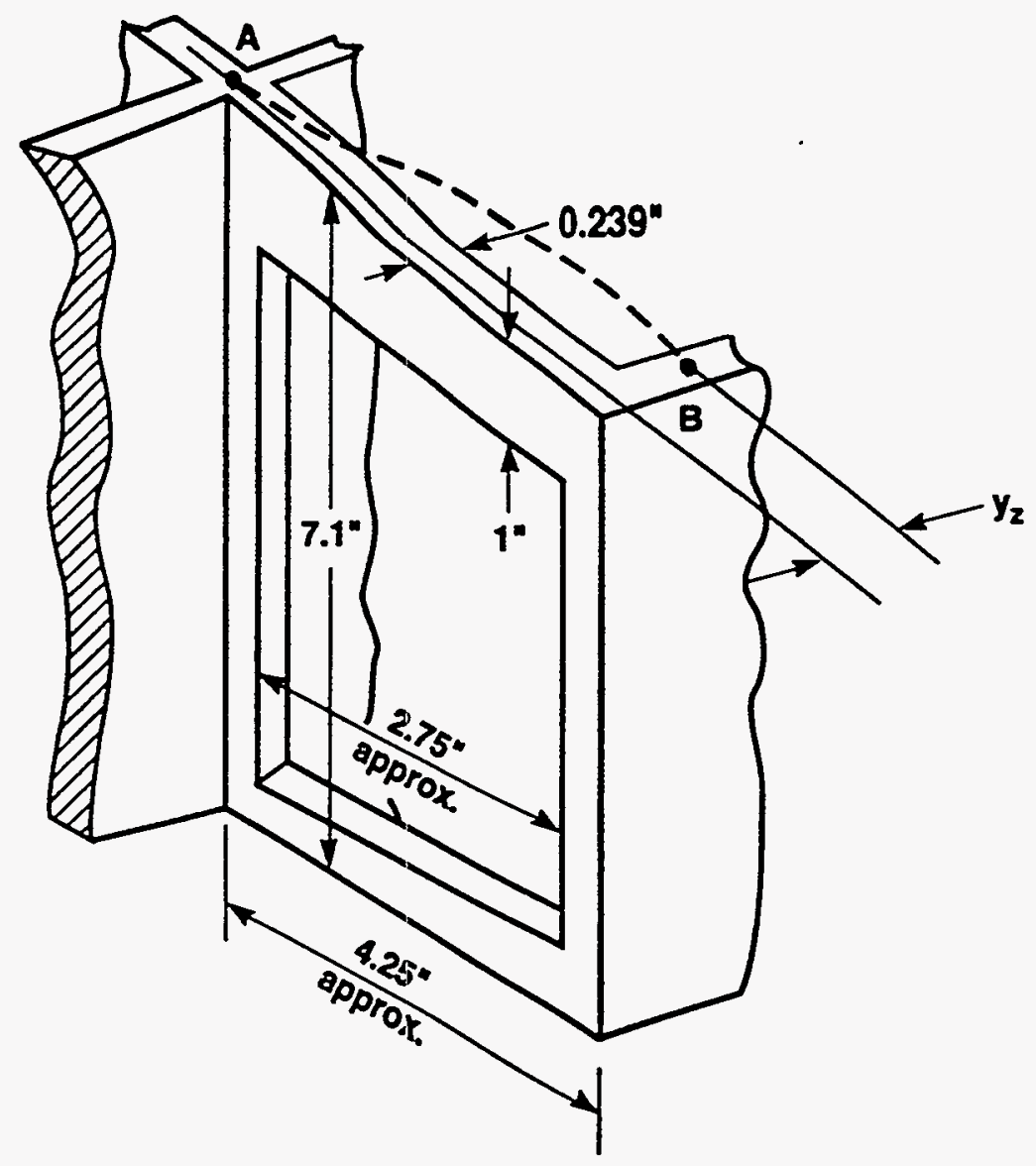

Figure 20. Window-type configuration. 
The most likely mode of beam behavior which can be used in this type of a structural configuration is depicted in Fig. 9. The term "critical" used in Fig. 19, has only a relative meaning because none of the stress levels generated by computer routines and closed-form approximations (so far) have been of a critical nature.

The approximate dimensions of the window-type structure for this problem are given in Fig. 20. The upper portion is shown to be displaced in the $y-z$ plane resulting in local bending with deflection of (B) end of the beam (in relation to A point) which can be described as

$$
\mathrm{Y}_{z}=\frac{\mathrm{WL}^{3}}{12 \mathrm{EI}}
$$

Since

$$
\begin{aligned}
\mathrm{S}_{\mathrm{b}} & =\frac{\mathrm{M}_{\mathrm{o}}}{\mathrm{Z}} \\
\mathrm{M}_{\mathrm{o}} & =\frac{\mathrm{WL}}{2} \\
\mathrm{~W} & =\frac{12 \mathrm{EI} \mathrm{Y}_{\mathrm{z}}}{\mathrm{L}^{3}} \\
\mathrm{I} & =\frac{\mathrm{bt}^{3}}{12} \\
\mathrm{Z} & =\frac{\mathrm{bt}^{2}}{6}
\end{aligned}
$$

then

$$
\begin{aligned}
S_{b} & =\frac{W L}{2 Z} \\
& =\frac{12 E I Y_{z} L}{L^{3} 2 Z} \\
& =\frac{6 E Y_{z}}{L^{2}} \times \frac{I}{Z} \\
& =\frac{3 E Y_{z} t}{L^{2}}
\end{aligned}
$$

from which

$$
\mathrm{Y}_{\mathrm{z}}=\frac{\mathrm{S}_{\mathrm{b}} \mathrm{L}^{2}}{3 \mathrm{Et}}
$$


The relevant dimensions can be taken from Fig. 20.

$$
\begin{aligned}
& \mathrm{L}=2.75 \text { in. } \\
& \mathrm{t}=0.239 \text { in. }
\end{aligned}
$$

It is evident that the width of the section, measuring approximately 1 in., does not enter the picture because the ratio (I/E) depends only on thickness ( $t$ ). Taking the maximum value of stress of 3070 psi from Fig. 18, as the maximum bending stress (conservative assumption), Eq. (52), yields

$$
\begin{aligned}
Y_{z} & =\frac{3070 \times 2.75^{2}}{3 \times 44 \times 10^{6} \times 0.239} \\
& =0.00074 \mathrm{in} . \quad(0.019 \mathrm{~mm})
\end{aligned}
$$

The degree of conservatism in this case can come from the perception that the maximum value of stress taken from Fig. 18 represents the von Mises-Hencky criterion and not just the normal uniaxial stress entering the equation $\left(S^{2}+3 \tau^{2}\right)^{1 / 2}$. The concentrated load $(W)$ can be estimated for the double-cantilever (or sinking support beam) as

$$
\mathrm{W}=2 \mathrm{ZS} \mathrm{S}_{\mathrm{b}} / \mathrm{L}
$$

Since

$$
\begin{aligned}
\mathrm{Z} & =1 \times 0.239^{2} / 6 \\
& =0.0095 \mathrm{in}^{3} \\
\mathrm{~W} & =2 \times 0.0095 \times 3070 / 2.75 \\
& =21.2 \mathrm{lb}
\end{aligned}
$$

The corresponding shear stress across a rectangular cross section, having dimensions $1.0 \mathrm{in}$., and $0.239 \mathrm{in}$., is

$$
\begin{aligned}
\tau & =1.5 \mathrm{~W} / \mathrm{bt} \\
& =1.5 \times 21.2 / 1 \times 0.239 \\
& =133 \mathrm{psi} \quad(0.92 \mathrm{MPa})
\end{aligned}
$$


This is a very small stress so that the original assumption of $3070 \mathrm{psi}$ as the normal uniaxial stress may well be justified in the foregoing calculation. Also, for the springmass model in a single degree of freedom, Eq. (48) gives

$$
\begin{aligned}
\mathbf{f} & =3.1 /(0.00074)^{1 / 2} \\
& =114 \mathrm{~Hz}
\end{aligned}
$$

So far, none of the stresses or deflections, based on closed-form solutions, indicate a problem with the computer-generated results.

\section{Comments on Fracture Resistance}

Material selection is one of the most difficult design tasks because of a mix of technical and nontechnical variables, created by the need of special properties for unique applications and environmental conditions. The problem of selection becomes even more involved when the elements of conventional knowledge and experience are intermixed with relatively new branches of science such as dislocation and fracture mechanics. And when the key physical and mechanical properties of structural materials, measured with the best available test apparatus and techniques, still indicate a considerable scatter, such as normally found with the $\mathrm{K}_{\mathrm{Ic}}$ results, we are entering the murky. waters of statistics. The information on fracture toughness of beryllium presented by Conrad et al. is impressive (including the list of references) and appears to indicate that current definition of $\mathrm{K}_{\mathrm{Ic}}$ may not apply to the results given in the paper, submitted more than 20 years ago. It is quite possible that there is no new published data on beryllium toughness today because the bulk of practical information related to fracture mechanics principles was developed around 1950s and 1960s. This is probably due to the fact that the last 20 years have seen the progress of $2 \mathrm{D}$ and $3 \mathrm{D}$ finite element computer studies, branded as the best design methodology available in spite of the horrendous expenditure of cost and time.

Be that as it may, the Conrad et al. paper, suggests the use of a new parameter $\mathrm{K}_{\max }$, instead of $\mathrm{K}_{\mathrm{Ic}}$, and the idea that $\mathrm{K}_{\max }$ can be predicted from certain parameters obtainable from a standard tensile test, appears to be optimistic. The major lesson from the paper is that hot-pressed beryllium is essentially a ductile material and that some thickness effect does exist. It is difficult, however, to reconcile that a ductile material can have extremely low elongation (in the range of a minimum of 0.6 percent to a maximum of 5.3 percent and the average of about 2 percent).

What is also interesting that there is no mention of Poisson's ratio. In general, dealing with metallics, low values of elongation and Poisson's ratio signify the behavior of a brittle material. Another point of contention is

$$
\mathrm{B} \geq 2.5\left(\frac{\mathrm{K}_{\mathrm{Ic}}}{\mathrm{S}_{\mathrm{y}}}\right)^{2}
$$


This boundary represents a conservative thickness requirement under plane-strain conditions. When the initial signs of a plastic deformation, for an elastic-perfectly plastic material, appear, the thickness criterion may be determined by

$$
B \geq 1.0\left(\frac{K_{I c}}{S_{y}}\right)^{2}
$$

According to the ASTM Standard Method of Test for $\mathrm{K}_{\mathrm{I}}$, the thickness must be defined by Eq. (55). Conversely, then, as the actual thickness of the plate is decreased, the notch toughness is expected to increase, leading to plane stress condition where the appropriate toughness is denoted by $\left(\mathrm{K}_{\mathrm{c}}\right)$. The extent of shear lip development at the fractured surface of the test specimen should be a qualitative indication of notch toughness. In experiments, this is mainly shown as the increased resistance to brittle fracture of a thinner plate. Perhaps a rather simple experiment could be made with the type of beryllium used in the frame manufacture for the project, in order to place the value of the new parameter $\left(\mathrm{K}_{\max }\right)$ in relation to the $\left(\mathrm{K}_{\mathrm{Ic}}\right)$ and $\left(\mathrm{K}_{\mathrm{c}}\right)$ ranges. The paper by Conrad et al. does not provide any direct evidence of this type. This is probably not surprising because the available data, produced at this time of publication, indicates considerable scatter which might have obscured any closer interpretation. In any case the Conrad et al. intent was to conduct a review and background for future work, rather than to provide specific data for design. In addition to this, the concern was about the fact that heat treatment can either raise or lower the fracture toughness level of beryllium, but even there, the scarcity of data prevailed.

Assuming that even an approximate estimate of the critical crack size is warranted, the most likely flaw will have the elliptical shape consistent with the surface crack theory and practice. The typical notation here is given in Fig. 21. The stress intensity factor for this case is

$$
\mathrm{K}_{\mathrm{I}}=2 \mathrm{~S}(\mathrm{a} / \mathrm{Q})^{1 / 2} \mathrm{M}_{\mathrm{B}}
$$

where $\left(\mathrm{M}_{\mathrm{K}}\right)$ is given by

$$
\mathrm{M}_{\mathrm{K}}=1.0+1.2\left(\frac{\mathrm{a}}{\mathrm{B}}-0.5\right)
$$

The parameter $(Q)$ is known as flaw shape factor given in Fig. 22. 


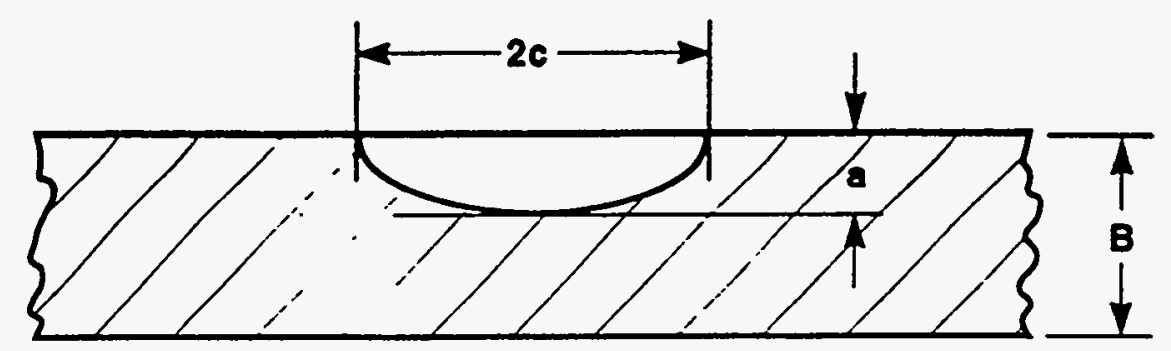

Figure 21. Notation for surface crack.

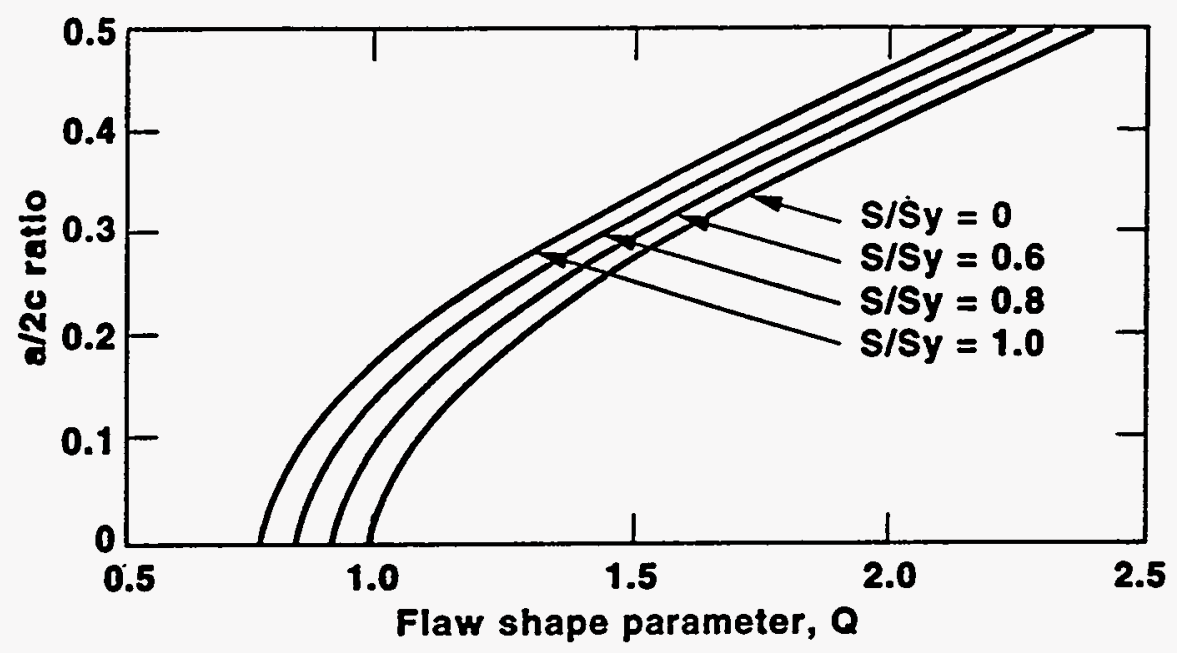

Figure 22. Design chart for $Q$.

The first check can be based on Eq. (55). Assuming $\mathrm{K}_{\mathrm{Ic}}=9 \mathrm{ksi}$ (in.) $)^{1 / 2}$ taken from general review of data by Conrad et al., and the maximum micro-yield (noted in presentations during RGS review, August 26, 1994) of 14 ksi, Eq. (55) gives

$$
\begin{aligned}
\mathrm{B} & =2.5\left(\mathrm{~K}_{\mathrm{Ic}} / \mathrm{S}_{\mathrm{y}}\right)^{2} \\
& =2.5(9 / 14)^{2} \\
& =1.03 \mathrm{in} .(26 \mathrm{~mm})
\end{aligned}
$$

In most critical areas of the support frame, the actual thickness of beryllium is smaller than the value of (B). Hence the plane strain condition does not exist and $9 \mathrm{ksi}$ is not a valid number. 
Assuming $(\mathrm{a} / 2 \mathrm{c})$ ratio of 0.25 and $\left(\mathrm{S} / \mathrm{S}_{\mathrm{y}}\right)=0.6$, the approximate value of flaw shape parameter follows from Fig. 22

$$
Q=1.36
$$

The correction factor from Eq. (58), is

$$
\begin{aligned}
\mathrm{M}_{\mathrm{K}} & =1.0+1.2\left(\frac{\mathrm{a}}{1.03}-0.5\right) \\
& =0.4+1.17 \mathrm{a}
\end{aligned}
$$

and from Eq. (57), the stress intensity factor is

$$
\mathrm{K}_{\mathrm{I}}=2 \mathrm{~S}\left(\frac{\mathrm{a}}{1.36}\right)^{1 / 2}(0.4+1.17 \mathrm{a})
$$

and for

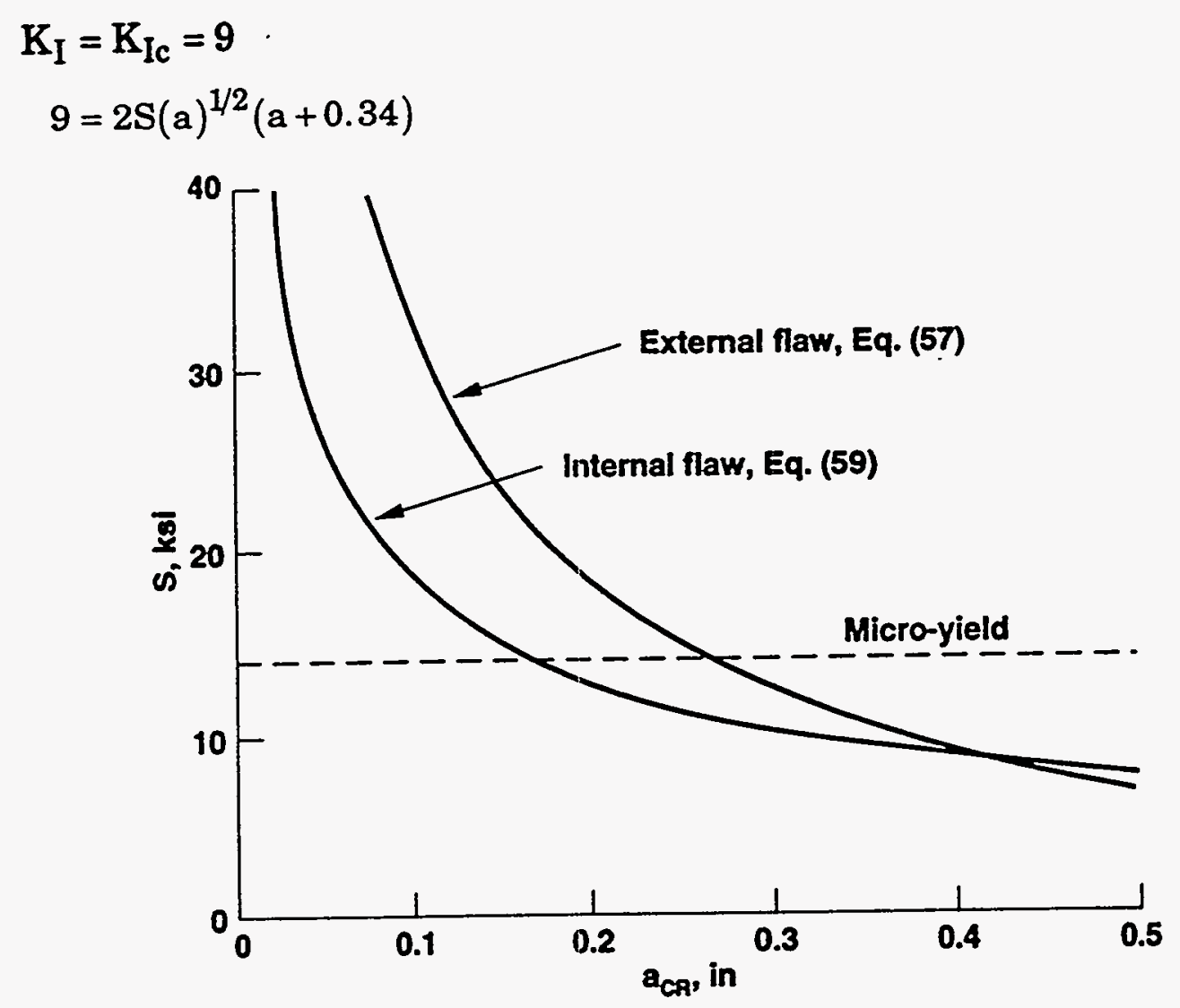

Figure 23. Stress versus critical crack size. 


$$
S=\frac{4.5}{(a)^{1 / 2}(a+0.34)}
$$

where $\mathrm{a}=\mathrm{a}_{\mathrm{CR}}$ for a given plane strain fracture toughness and nominal applied stress in tension. This relationship is plotted in Fig. 23.

For an embedded crack of elliptical geometry, the stress intensity factor is

$$
\mathrm{K}_{\mathrm{I}}=1.77 \mathrm{~S}(\mathrm{a} / \mathrm{Q})^{1 / 2}
$$

The plot for this case is given in Fig. 23. Based on the foregoing sample calculations, the applied stress equal to micro-yield of $14 \mathrm{ksi}$, can tolerate a crack depth of 0.25 in. The corresponding crack length in this configuration would be 1.0 in.

This model was taken on the premise that we have a valid $\left(\mathrm{K}_{\mathrm{Ic}}\right)$ parameter. This is certainly not the case stated in the paper by Conrad et al.

\section{Summary and Conclusions}

In retrospect, the entire report was concerned with only the simplest models and equations in order not to get lost in too many numerical details and time-consuming derivations so that the primary goal of a comparison between the machine and handcranked solutions is not obscured.

It soon became obvious that the design of the support frame was governed by the rigidity rather than strength, starting with the "half-ring model" of the equivalent mass and utilizing proven design equations for out-of-plane analysis of forces and displacements. The important feature of the simplistic formulas was that the out-ofplane deflection could be expressed in terms of the ratio of the flexural and torsional rigidity. Since the various parameters for the complex frame geometry had to vary from point to point it was necessary to make rather crude, approximate decisions, on the premise that the selection of the majority of "ball park" values of stresses and deflections could be considered as conservative. The magnitudes of the second moments (inertia) were extracted from the computerized data bank. The torsion properties of sections, however, had to be hand-calculated for the specific geometries.

The next, important closed-form solution employed a very elementary beam formula for a "sinking support model," sometimes referred to as the shear model. The plate members between the rigid supports behaved as double-cantilevers, and the sum of all the deflections had to be corrected for the actual length of the circumference and the effect of curvature. This was necessary because the cumulative deflection of all double-cantilevers was a summation of the deflections of individual straight members.

Another independent closed-form solution was based on the "three point support ring" involving a rather complicated set of trigonometric functions, derived and proved 
in practice, for $n=3$, where ( $\mathrm{n}$ ) is the number of the supports. The design tables are given for the several values of $(n)$, and the particular solution for $n=2$, reduces to an identical result with that obtained from the "half-ring model." The change from two to three supports is rather significant, showing how the maximum stresses and deflections can decrease with an increase in the number of supports.

The theoretical solution of a pin-jointed circular arch under uniform in-plane loading was used as a quick method of the approximate-check of lateral (horizontal) rigidity of the support frame under dynamic loading.

The analytical results for the plate corners, generated with the aid of the computer code, were basically limited to the local maximum stresses found at the plate edges. The closed-form approach to this problem included the maximum deflections and local frequencies based on the single degree of freedom. Additional calculations provided a simple check of the elastic stability of individual frame elements. The portions of the window-type configuration were analyzed using the basic stress and deflection formulas derived from a double-cantilever equation.

The last section was devoted to the applicable elements of the linear elastic fracture mechanics and the review of the early paper dealing with the prediction of the fracture resistance of beryllium. The basic question to be resolved included the plane strain versus plane stress considerations in the light of current practice. Included also were design formulas and curves for estimating the stress intensity factor for an elliptical surface crack. The variation of the applied, nominal stress as a function of the critical crack length was plotted for the assumed external and internal flaw shapes.

The conclusion to be drawn from an independent use of the conservative closedform assumptions and hand calculations is that the computer-generated results from the LLNL approved codes are in general agreement with the conventional theories of strength and elasticity of materials. Although this comparison was limited to a relatively small number of preselected locations of the support frame there is sufficient confidence to infer that the expected rigidity of the entire frame is high and the critical stresses are low. This high/low combination of the frame design features is certainly to be recommended for the type of the mission and the nature of the material involved. The only remaining issues for further attention are fracture toughness, fabrication control, and certification of the final product.

\section{References}

Barsom, F. M., and S. T. Rolfe, Fracture and Fatigue Control in Structures, PrenticeHall, Inc., Englewood Cliffs, N.J., 1987.

Blake, A., Design of Curved Members for Machines, Robert E. Krieger, Huntington, N.Y., 1979.

Conrad, H., F. Hurd, and D. Woodard, "The Fracture Toughness of Beryllium," Journal of Testing and Evaluation, JTEVA, Vol. 1, No. 2, 1973.

Timoshenko, S., Theory of Elastic Stability, Engineering Societies Monograph, McGraw-Hill, New York, 1936. 